\title{
Subsurface Water Oceans on Icy Satellites: Chemical Composition and Exchange Processes
}

\author{
Frank Sohl • Mathieu Choukroun · Jeffrey Kargel • \\ Jun Kimura • Robert Pappalardo • Steve Vance • \\ Mikhail Zolotov
}

Received: 24 August 2009 / Accepted: 1 March 2010 / Published online: 13 April 2010

(C) Springer Science+Business Media B.V. 2010

\begin{abstract}
The state of knowledge about the structure and composition of icy satellite interiors has been significantly extended by combining direct measurements from spacecraft, laboratory experiments, and theoretical modeling. The existence of potentially habitable liquid water reservoirs on icy satellites is dependent on the radiogenic heating of the rock component, additional contributions such as the dissipation of tidal energy, the efficiency of heat transfer to the surface, and the presence of substances that deplete the freezing point of liquid water. This review summarizes the chemical evolution of subsurface liquid water oceans, taking into account a number of chemical processes occuring in aqueous environments and
\end{abstract}

F. Sohl $(\bowtie)$

Institute of Planetary Research, German Aerospace Center (DLR), Rutherfordstr. 2, 12489 Berlin, Germany

e-mail: frank.sohl@dlr.de

M. Choukroun · R. Pappalardo $\cdot$ S. Vance

Jet Propulsion Laboratory, Caltech, MS 79-24, 4800 Oak Grove Drive, Pasadena, CA 91106, USA

M. Choukroun

e-mail: mathieu.choukroun@jpl.nasa.gov

R. Pappalardo

e-mail: robert.pappalardo@jpl.nasa.gov

S. Vance

e-mail: svance@jpl.nasa.gov

J. Kargel

Department of Hydrology, University of Arizona, Tuscon, AZ 85721, USA

e-mail: kargel@hwr.arizona.edu

J. Kimura

Department of Cosmosciences, Hokkaido University, Nishi 8, Kita 10, Kita-Ku, Sapporo 060-0810, Japan

e-mail: junkim@ep.sci.hokudai.ac.jp

M. Zolotov

School of Earth and Space Exploration, Arizona State University, Tempe, AZ 85287-1404, USA

e-mail: zolotov@asu.edu 
partly related to material exchange with the deep interior. Of interest are processes occuring at the transitions from the liquid water layer to the ice layers above and below, involving the possible formation of clathrate hydrates and high-pressure ices on large icy satellites. In contrast, water-rock exchange is important for the chemical evolution of the liquid water layer if the latter is in contact with ocean floor rock on small satellites. The composition of oceanic floor deposits depends on ambient physical conditions and ocean chemistry, and their evolutions through time. In turn, physical properties of the ocean floor affect the circulation of oceanic water and related thermal effects due to tidally-induced porous flow and aqueous alteration of ocean floor rock.

Keywords Outer solar system · Water oceans · Oceanic composition · Chemical evolution · Organic compounds · High-pressure ices · Clathrate hydrates · Hydrothermal activity $\cdot$ Porous rock $\cdot$ Serpentinization · Europa $\cdot$ Ganymede $\cdot$ Callisto $\cdot$ Titan $\cdot$ Enceladus

\section{Introduction}

Based on the notion that water ice is one of the major constituents in the outer solar system, early models of condensation and icy satellite formation predicted that incorporation of abundant water ice and silicate rock containing radionuclides could have led to ice melting and the formation of extended liquid water mantles beneath conductive outer ice shells (Lewis 1971, 1972, 1973). The maintenance of these global subsurface liquid water oceans was found to be closely related to a satellite's internal structure, chemical composition, and thermal history (Consolmagno and Lewis 1976, 1977, 1978). Later, it was argued that temperature increase with depth would affect the rheological properties of the outer ice shell and the efficiency of subsolidus convection controlling the thermal history of the deep interior (Schubert et al. 1981, 1986; Spohn and Schubert 2003). As a consequence of efficient convective cooling, the radial extent of subsurface water oceans would be strongly diminished and could eventually lead to freezing. Contrarily, laboratory experiments indicated that the melting temperature of ice will be significantly reduced by small amounts of salts and/or incorporated polar solutes such as methanol and ammonia (e.g. Croft et al. 1988; Grasset and Pargamin 2005). The latter species are present in comets and may be present in other icy bodies in the outer solar system.

The state of knowledge about the structure and composition of icy satellite interiors has improved considerably in the late 70 s and mid 80s, when the Voyager spacecraft flew by Jupiter, Saturn, Uranus, and Neptune, followed by the advent of the Galileo spacecraft in the Jovian system (1995-2003) and the Cassini spacecraft in the Saturnian system (since 2004). Voyager observations of the Jovian moons Io and Europa and, to a lesser extent, Ganymede suggested tidal heating to be a major heat source, possibly resulting in near-surface viscous deformation of warmed ice and cryovolcanic resurfacing (e.g. Johnson 2005, and references therein). An outstanding finding of the Galileo mission, based on the interpretation of magnetometer data (e.g. Khurana et al. 1998; Kivelson et al. 1999, 2000), was the detection of induced magnetic fields in the vicinity of Europa, Callisto, and possibly Ganymede (Kivelson et al. 2004). The observed magnetic signatures suggest the presence of electrically conducting reservoirs of salty liquid water beneath the satellites' outer icy shells that may contain more water than the terrestrial oceans combined. Galileo imagery of Europa has been interpreted in terms of endogenic morphological features (e.g. Greeley et al. 2004) and compositional heterogeneity (e.g. McCord et al. 1999; Pappalardo et al. 1999; Carlson et al. 1999; Prockter et al. 2010, this issue; Dalton et al. 2010, this issue). The orientation of the 
satellite-wide, symmetric fracture pattern has been attributed to nonsynchronous rotation of the outer icy shell across Europa's permanent tidal bulge (Geissler et al. 1998; Kattenhorn 2002). Particularly strike-slip behavior and plate rotation near the anti-Jovian point (Schenk and McKinnon 1989) and episodic plate separation and fracture infill (Sullivan et al. 1998) is taken as geologic evidence that the outer ice shell is decoupled from Europa's deep interior due to the existence of a subsurface water ocean (Greenberg et al. 1998, 2002). Schenk et al. (2008) have attributed current locations of broad arcuate troughs and depressions to the episodic reorientation of Europa's floating ice shell by true polar wander of $\sim 80^{\circ}$. The detection of non-icy, sulfur-bearing, and hydrated colored materials in endogenic surface features on Europa and Ganymede suggests an oceanic origin of these surface compounds (e.g. McCord et al. 1999, 2001). Cassini synthetic aperture radar (SAR) imagery of Titan has been interpreted in terms of non-synchronous rotation. Provided the satellite's outer ice shell were decoupled from the deep interior by a liquid water layer, Titan's supersynchronous spin could be attributed to seasonal exchange of angular momentum with the dense superrotating atmosphere (Lorenz et al. 2008). The detection of alkali salts in Saturn's E ring (Postberg et al. 2009), formed through eruptive activity on Enceladus (Schmidt et al. 2008), indicates past or present aqueous activity in the satellite's interior. Although a large global ocean may not exist on present-day Enceladus, sodium and potassium could have been leached from rocks early in history and accumulated at the ice-rock interface upon ocean freezing (Zolotov 2007). Geologically recent tidal heating below the south pole of Enceladus may involve the salts in eruptive plume activity.

In this review, we focus on the chemical development of subsurface liquid water oceans, physical constraints on aqueous circulation, and related exchange processes involving deep satellite interiors. In Sect. 2, we discuss some aspects of the chemical evolution of aqueous fluids and primordial oceans. Section 3 is devoted to water-ice interaction, involving segregation of high-pressure ice polymorphs and clathrate hydrates at ice-water boundaries. In Sect. 4, we discuss the impact of physical ocean floor properties such as permeability, porosity, and compressibility on Europa-like circulation of oceanic water and related thermal effects due to porous flow and aqueous alteration close to the rock-water boundary. Section 5 discusses possible implications for the compositional stratification of different classes of icy bodies. Discussion and conclusions are presented in Sect. 6.

\section{Chemical Evolution}

Pathways of oceanic chemical evolution are mainly affected by the bulk composition and thermal history of a satellite. The bulk composition constitutes the ratios between rocks, water ice, non-water volatiles, and organic compounds. Throughout history, the chemical evolution of subsurface water oceans has been affected by the degree of ice melting, the extent and duration of chemical interactions between rocks and liquid water, degassing of the deep interior and oceanic water, freezing and thawing cycles, and secondary inorganic and organic precipitation. A great variety of these factors and processes among icy satellites implies diverse pathways of their aqueous evolution.

\subsection{Formation and Early Chemical Evolution of Aqueous Fluids}

The satellites of the giant planets are thought to have originated from a compositionally diverse mixture of grains that slowly accumulated from the surrounding solar accretion disk (Canup and Ward 2002, 2009; Mosqueira et al. 2010, this issue; Coradini et al. 2010, this 
issue). Contrary to chondrites, these rocky materials would not have been thermally reprocessed in the accretion disk and would have consisted of dust particles $(\lesssim 1 \mu \mathrm{m}$ in diameter) without chondrules. A deficiency of chondrules suggests that accreted mineral dust was closer to solar composition than materials that formed asteroids. The predominant accretion of solids as dust also implies that minerals would not have been aqueously altered prior to accretion. Despite some chemical differences, icy satellites might have accreted rocky materials similar to those present on asteroids, together with abundant amorphous silicate phases, ices, and organic compounds. The rocky crystalline solids consisted of reduced and anhydrous products of solar nebula processes (mainly $\mathrm{Fe}-\mathrm{Ni}$ metal, $\mathrm{FeS}, \mathrm{Mg}$ - and $\mathrm{Ca}$-silicates, and $\mathrm{Ca}-\mathrm{Al}$-oxides), organic matter, and minor presolar grains. By analogy with carbonaceous chondrites (e.g. Sephton 2002), the majority of accreted organic matter was in a polymer in which polyaromatic groups are linked by $\mathrm{O}-, \mathrm{N}-$, and $\mathrm{S}$-bearing aliphatic units. If accreted, cometary-type materials (e.g. Bockelée-Morvan et al. 2004) also delivered $\mathrm{CO}_{2}$, $\mathrm{CO}$, methanol, ethane, acetylene, ammonia, $\mathrm{H}_{2} \mathrm{~S}$, formaldehyde, and condensed $\mathrm{C}-\mathrm{H}-\mathrm{O}-\mathrm{N}$ rich organic species. The initial composition of icy satellites may range between those of carbonaceous (C, D, P) asteroids (McKinnon and Zolensky 2003) and comets with increasing heliocentric distance. An increase in the abundance of $\mathrm{C}$ and $\mathrm{N}$ species with heliocentric distance reflects the increasing similarity of outer solar system bodies with the composition of the solar photosphere, which is significantly enriched in these elements compared to CI carbonaceous chondrites (Palme and Jones 2003).

Some satellites may have formed lately by accreting planetesimals (similar to $\mathrm{CI} / \mathrm{CM}$ carbonaceous chondrites) that were aqueously altered and contained hydrated and oxidized phases and salts (phyllosilicates, magnetite, Fe-Ni sulfides, carbonates, phosphates, chlorides, and sulfates; Kargel 1991). For example, Kuskov and Kronrod (2005) consider L/LLchondrites as the most likely analogue case for Europa's bulk iron-silicate composition. This compositional model would provide mean densities and dimensionless moment-of-inertia factors for Europa's silicate mantle and core that are similar to Io's, while carbonaceous chondrite compositional models would yield significantly higher values. Taking into account these cosmochemical constraints, a three-layer interior structure can be considered as the most plausible, with core radii ranging from 470 to $640 \mathrm{~km}$, corresponding to bulk $\mathrm{Fe} / \mathrm{Si}$ ratios of 0.9 to 1.3 (Kuskov and Kronrod 2005), i.e. less than that for CI carbonaceous chondrites of $1.7 \pm 0.1$ (Kerridge and Matthews 1988).

Deposition of impact energy during accretion, decay of radionuclides, energy release through water-ice differentiation, and heat of mineral hydration reactions are major heat sources for ice melting (see Hussmann et al. 2010; Schubert et al. 2010, this issue). Contrary to earlier scenarios (Schubert et al. 1986; Stevenson et al. 1986), gas-starved accretion (e.g. Canup and Ward 2009) does not provide much accretion energy, and impact melting may only be related to large planetesimals hitting large satellites. If satellite accretion was accomplished within $\sim 8 \mathrm{Ma}$ after the formation of Ca-, Al-rich inclusions (CAIs) in the solar nebula, heat production through the decay of short-lived ${ }^{26} \mathrm{Al}\left(\tau_{1 / 2} \approx 0.7 \mathrm{Ma}\right)$ would surpass that of long-lived radionuclides $\left({ }^{235} \mathrm{U},{ }^{238} \mathrm{U},{ }^{40} \mathrm{~K},{ }^{232} \mathrm{Th}\right)$. There is no clear understanding of how the amount of accreted ${ }^{26} \mathrm{Al}$ may have varied with heliocentric distance. Early differentiated asteroids in the inner asteroid belt (Scott 2007) and some Saturnian satellites such as Iapetus (Castillo-Rogez et al. 2007) may have accreted a significant amount of ${ }^{26} \mathrm{Al} \mathrm{a}$ few Ma after CAI formation, while partial differentiation of Callisto (McKinnon 2006) may suggest late accretion without abundant ${ }^{26} \mathrm{Al}$. Despite the lower but more persistent heat production by long-lived radionuclides, melting may occur on larger icy satellites and even on small bodies such as Enceladus (Schubert et al. 2007).

Due to the gradual increase in temperature over time, early melt formation could have occurred within icy satellite interiors (see Schubert et al. 2010, this issue). In the presence of 
non-water ice components detected or expected in the outer solar system (e.g. $\mathrm{CH}_{3} \mathrm{OH}, \mathrm{NH}_{3}$, ethylene glycol, $\mathrm{HCl}, \mathrm{H}_{2} \mathrm{~S}, \mathrm{CO}, \mathrm{CO}_{2}$ ), eutectic solutions at temperatures well below $273 \mathrm{~K}$ would have formed. Heat-producing silicate particles then would have been surrounded by eutectic brine pockets. First solutions could have formed at temperatures as low as $\sim 175 \mathrm{~K}$, which corresponds to the $\mathrm{NH}_{3}-\mathrm{H}_{2} \mathrm{O}$ eutectic (e.g. Desch et al. 2009). Melting of $\mathrm{HCl}$ hydrates at $\sim 186 \mathrm{~K}$ (Zolotov and Mironenko 2007a) would result in low pH, facilitating dissolution of mineral phases and amorphous silicate materials. This process enriched solutions by cations and caused some secondary precipitation (e.g. amorphous silica) and neutralization of fluids (Zolotov and Mironenko 2007b). Subsequently, the increase in temperature caused dilution of these primordial solutions and the formation of larger melt pockets and liquid reservoirs.

Heating and melting of ice is paramount to outward migration of aqueous solutions and rock particle settling toward the center, eventually leading to internal ice-rock differentiation and cryovolcanic resurfacing. Provided ice-rock differentiation had run to completion, silicate mantles (Europa, Ganymede, Enceladus) overlain by water ice/liquid shells would form (e.g. Schubert et al. 1986, 2007, 2009). Additional segregation of an Fe-rich core (Ganymede, Europa) is thought to be accompanied by some dehydration of phyllosilicates within the silicate mantles formed earlier. Depending on the degree of internal differentiation of ice and rock, primordial oceans on large ice-rich moons (Ganymede, Callisto, Titan) could be sandwiched between outer ice shells and high-pressure ice layers below. This separation would inhibit further compositional evolution of these liquid reservoirs. Contrary, liquid water was likely accumulated in the outer parts of smaller satellites (Enceladus, Europa, Triton) where the chemical evolution of subsurface water oceans would proceed in contact with rocky seafloors and/or oceanic sediments (e.g. Schubert et al. 2007, 2009).

Once initial solutions first appeared in the presence of ice, early liquid water on icy satellites participated in competitive oxidation and hydration reactions, analogous to aqueous processes on chondrite parent bodies (e.g. Brearley 2006). Reaction (1) exemplifies oxidation and reaction (2) illustrates hydration,

$$
\begin{aligned}
& 3 \mathrm{Fe}^{0} \text { (metal) }+4 \mathrm{H}_{2} \mathrm{O}(\mathrm{l}) \rightarrow \mathrm{Fe}_{3} \mathrm{O}_{4} \text { (magnetite) }+4 \mathrm{H}_{2} \\
& \mathrm{Mg}_{2} \mathrm{SiO}_{4} \text { (forsterite) }+\mathrm{MgSiO}_{3} \text { (enstatite) }+2 \mathrm{H}_{2} \mathrm{O}(\mathrm{l}) \\
& \quad \rightarrow \mathrm{Mg}_{3} \mathrm{Si}_{2} \mathrm{O}_{5}(\mathrm{OH})_{4} \text { (serpentine) }
\end{aligned}
$$

Note that metal was supplied by Fe-Ni alloys (kamacite) and a substantial portion of silicate reagents was amorphous. Phyllosilicates (serpentine, cronstedtite, saponite, etc.) and tochilinite (a hydrated Fe-Ni sulfide) formed through hydration. Heat released by hydration reactions contributed to the thermal balance early in a satellite's thermochemical evolution (e.g. Schubert et al. 2007). Oxidation led to formation of ferrous (serpentine, saponite) and ferric (magnetite, cronstedtite) minerals, sulfides (tochilinite, pyrrhotite, pentlandite), Ni-rich alloys, chromite, and phosphates. Note that $\mathrm{Fe}^{2+}$ and $\mathrm{Fe}^{3+}$ solutes formed through aqueous oxidation of $\mathrm{Fe}-\mathrm{Ni}$ metal and were also incorporated into secondary silicates.

Hydrogen $\left(\mathrm{H}_{2}\right)$ could have formed through mineral oxidation by water, for example, via reaction (1). Separation and rapid release of $\mathrm{H}_{2}$ to space through fractures in thin icy shells (Europa and Enceladus; Glein et al. 2008; Zolotov and Kargel 2009) would have favored further oxidation reactions. Despite $\mathrm{H}_{2}$ escape, aqueous systems would not have re-equilibrated under more oxidizing conditions because redox reactions are kinetically inhibited at low temperatures. On large icy satellites (Ganymede, Titan, Triton), oxidation was limited because of restricted $\mathrm{H}_{2}$ escape through thicker ice shells. Therefore, it is unlikely that highly oxidized species (e.g. sulfates) were able to form on large icy satellites. 
In addition to dissolved volatiles and acids, the compositions of primordial oceans were a result of low-temperature $(\leq 273 \mathrm{~K})$ aqueous alteration of rocks, often in the presence of partially melted ice. Early in these water-rock interaction processes, aqueous compositions could have varied rapidly, as primary minerals alter with different rates (Zolotov and Mironenko 2007b). With time, neutralization of initial acid solutions and saturation of oceanic water with respect to secondary minerals led to stabilization of oceanic compositions. Early acidic $\mathrm{Fe}-\mathrm{Mg}-\mathrm{Ca}-\mathrm{Cl}$ solutions evolved toward alkaline $\mathrm{Na}-\mathrm{OH}-\mathrm{Cl}$ solutions. Eventually, oceanic solutions reached acid-base equilibration with altered rocks, which were rich in secondary phyllosilicates and contained magnetite, sulfides and carbonates (e.g. Zolotov 2007, 2008). However, oxidized species (e.g. $\mathrm{Fe}^{3+}$, carbonate and sulfate, if present) could have coexisted metastably with reduced compounds $\left(\mathrm{Fe}^{2+}\right.$, sulfide and native sulfur, organic matter). Multiple redox disequilibria (e.g. Zolotov and Shock 2004) may have supported metabolism of chemotrophic organisms, if they were present.

Chemical equilibrium models demonstrate that early oceans on icy satellites could have been cold, alkaline, rich in $\mathrm{Na}$ and $\mathrm{Cl}$, depleted in $\mathrm{Mg}$ and $\mathrm{S}$, and not saline (e.g. Zolotov 2007, 2008). Sulfur was in sulfide form $\left(\mathrm{HS}^{-}+\mathrm{S}^{2-}\right.$ ) and its low concentration was controlled by the solubility of Fe sulfides (McKinnon and Zolensky 2003; Zolotov 2008). Sulfate sulfur can only be present if aqueously altered planetesimals accreted (Kargel et al. 2000). The concentration and activity of dissolved $\mathrm{H}_{2}$ were mostly dependent on pressure and possible escape to space. On smaller moons (Enceladus, Europa) oceanic $\mathrm{H}_{2}$ could have escaped easily compared to deeply located oceans on larger satellites (Titan, Ganymede, Triton). Extremely reduced conditions at high pressure in those oceans could have favored stability of $\mathrm{CH}_{4}$ and its formation through hydrogenation of organic and inorganic (e.g, $\mathrm{CO}_{2}$ ) species (Zolotov et al. 2005). Convection in the upper icy shell, if present, may have delivered some $\mathrm{H}_{2}$ and $\mathrm{CH}_{4}$ toward the surfaces and atmospheres (Titan, Triton).

On large and small satellites, aqueous $\mathrm{C}$ species could have been presented by methanol $\left(\mathrm{CH}_{3} \mathrm{OH}\right), \mathrm{HCO}_{3}^{-}, \mathrm{CO}_{3}^{2-}$, and formate $\left(\mathrm{HCOO}^{-}\right)$, which forms through hydrolysis of $\mathrm{CO}$ and $\mathrm{HCN}$, and reactions among single $\mathrm{C}$ species (methanol, formaldehyde, and carbonate/bicarbonate ions; Seewald et al. 2006). Note that the abundance and speciation of aqueous $\mathrm{C}$ species were limited by inefficient low-temperature dissolution of primary organic matter and by low rates of redox reactions. $\mathrm{NaCl}$, methanol, and ethylene glycol could be the major oceanic solutes, thereby favoring much longer ocean lifetime due to significant freezing point depletion. On some satellites in the Saturnian system and beyond, ammonia is thought to be present (Waite et al. 2009), thereby accounting for relatively cold subsurface water oceans because of the significant melting point depletion (Hussmann et al. 2006). However, the abundance of ammonia may be low or even non-existent; and nitrogen, e.g. present in Titan's atmosphere and at Triton's surface, may result from oxidation of organic compounds deep within each satellite.

\subsection{Chemical Evolution of Primordial Oceans}

Pathways of subsequent oceanic evolution were mostly dependent on the scale, timing, and locations of heat production in the satellite interiors. On large and/or early-formed satellites, continuous supply and transfer of heat within the silicate mantles could have induced hydrothermal circulation, dehydration of previously formed minerals, and further alteration of organic matter.

If occurred, thermal dehydration of early-formed minerals (phyllosilicates, tochilinite) would have caused upward migration of hydrothermal fluids, thereby affecting ocean mass and composition. As for primordial oceans, the composition of ocean-forming fluids was 
chiefly controlled by chemical interactions in the uppermost rock layers during and after core dehydration, when hydrothermal processes took place as oceanic water circulated through permeable rocks below the ocean-rock boundary. The release of tidal heat and/or magmatic activity (Europa?) in subjacent rocks enhanced the circulation. As a result, hot aqueous fluids with inorganic and organic species induced changes in ocean compositions. In turn, hydrothermal circulations caused deposition of some oceanic species (e.g. Zolotov 2007; Zolotov and Kargel 2009). However, on large satellites (Titan, Ganymede, Triton), hydrothermal circulation was unlikely because of impermeable rocks and separation of oceans from silicate mantles by high-pressure ices. On Europa, hydrothermal circulation could have affected only suboceanic rocks, and on smaller bodies (Enceladus) circulation may have affected the entire silicate mantle (Vance et al. 2007; Glein et al. 2008, and Sect. 4 of this paper).

Hydrothermal processes further altered the mineralogy of permeable rocks and favored oxidation of rocks, fluids, and organic compounds, and $\mathrm{H}_{2}$ generation. High-temperature fluids were rich in sulfide species, and the mixing of hydrothermal fluids with oceanic water led to the precipitation of metal sulfides (e.g. pyrite) at ocean-rock interfaces (e.g. Zolotov 2007). The upward transport (bubbling, diffusion, convection) and escape of $\mathrm{H}_{2}$ oxidized smaller icy moons (Europa, Enceladus; Zolotov and Shock 2004; Glein et al. 2008). Hightemperature and low- $f \mathrm{H}_{2}$ conditions increased the carbonate $\left(\mathrm{CO}_{2}+\mathrm{HCO}_{3}^{-}+\mathrm{CO}_{3}^{2-}\right)$ and sulfate concentrations of hydrothermal fluids. The oxidation of sulfides to sulfates favored the partial dissolution of Mg-silicates, which could have led to the formation of Mg-sulfates in severely oxidized satellites, such as Europa (Zolotov and Kargel 2009). Like in parent bodies of $\mathrm{CI}$ carbonaceous chondrites, the high $\mathrm{Mg} / \mathrm{Ca}$ ratio and precipitation of Ca-bearing carbonates could have prevented major precipitation of sulfates in low-solubility Ca-sulfates (gypsum, anhydrite). As a result, Mg-sulfates could have become abundant among oceanic solutes (at least on Europa).

Presumably, the slow escape of $\mathrm{H}_{2}$ allowed mineral assemblages to control the oxidation state $\left(f \mathrm{H}_{2}\right)$ of hydrothermal systems. Prolonged thermal history of Europa over which $\mathrm{H}_{2}$ could have escaped, all support profound net oxidation of at least upper rock layers and accumulation of oxidized (carbonate and possibly sulfate) aqueous species in the ocean (Zolotov and Kargel 2009). On smaller moons (Enceladus; Glein et al. 2008), this process may have not occurred because of lower temperatures and an early cessation of thermal processes.

Hydrothermal conditions on small satellites favored further transformation of carbon species in fluids and permeable suboceanic rocks. If supplied by accretion, carbon monoxide could have converted to formic acid, carbonate species, methanol and some methane (Seewald et al. 2006). Hydrous pyrolysis of the high-molecular-weight polymer caused oxidation of aliphatic groups, partially liberation of aromatic molecules and led to the formation of oxygen-bearing compounds (carboxylic and amino acids, alcohols; Sephton 2002). Further increase in temperature favored oxidation of organic matter to carbonate species and $\mathrm{N}_{2}$, and eventually led to graphitization of the polymer, as observed in metamorphosed chondrites (e.g. Brearley 2006). If $\mathrm{H}_{2}$ escape was restricted, mineral-catalyzed Fisher-Tropsch like synthesis of hydrocarbons and $\mathrm{CH}_{4}$ may have occurred. However, asteroidal samples (chondrites) do not reveal signs of Fisher-Tropsch type synthesis (Alexander et al. 2007) and the majority of organic species on small moons (Europa, Enceladus) could be presented by primordial and/or transformed primordial species. Note that some methane could have formed though thermal decomposition of primordial organic matter, especially in the presence of a hot aqueous phase. As a result of multiple organic and organic-inorganic interactions, an array of aromatic, aliphatic, and N-, O-, S-bearing organic species, and methane 
could have been delivered into water oceans. Highly soluble compounds (acids, alcohols) may have made multiple passes through hydrothermal systems causing further oxidation of organic matter in rocks and solutions. In contrast, hydrocarbons could have been exsolved from cold fluids (and ocean waters) and formed floating organic layers below the icy shells (e.g. Zolotov and Kargel 2009). Higher-density organic compounds (tar) could have been accumulated at oceanic floors. It is not excluded that oceanic waters could have been isolated from rock by heavy organic condensates.

Based on energy balance constraints, Hussmann and Spohn (2004) and Tobie et al. (2005a) studied the coupling between ice shell thickness variations and tidal heat production in the presence of resonant satellite orbits (e.g. Laplace resonance of Io, Europa, and Ganymede; see Hussmann et al. 2010, this issue). Oscillations of Europa's ice shell thickness would notably affect oceanic salinity, composition, temperature, and the mineralogy of suboceanic rocks (Zolotov and Kargel 2009). Low tidally-induced activity would cause some freezing of the icy shell, increasing the salinity of oceanic water, mineral precipitation and exsolution of gases. Higher salinities will depress freezing temperatures and imply colder oceanic water. In contrast, intense release of tidal heat would lead to dilution of oceanic water through ice melting and some dehydration of solids. Moderate changes in ice thickness may cause precipitation or dissolution of Ca-carbonates and sulfates, pyrite, ferric hydroxides/oxyhydroxides, amorphous silica, clay minerals and phosphates without changing concentrations of corresponding solutes. However, concentrations of $\mathrm{Cl}, \mathrm{SO}_{4}^{2-}$ (if present), $\mathrm{Mg}$, and $\mathrm{Na}$ may not be efficiently maintained by solution-mineral reactions, and concentrations of these solutes would vary with changes in ice shell thickness. For example, freezing of $50 \%$ of oceanic water in unsaturated ocean models (e.g. Zolotov and Shock 2001) would not lead to precipitation of chlorides and sulfates of $\mathrm{Mg}$ and $\mathrm{Na}$, while double oceanic salinity. Precipitation of abundant salts can only be possible after freezing of a significant portion of oceanic water as shown for Europa (Kargel et al. 2000; Zolotov and Shock 2001) and Enceladus (Zolotov 2007). Note, however, that near-eutectic low-temperature brines should not be referred to as water oceans. Instead, near-eutectic solutions may represent low-volume brine pockets or be a small part of an ice-salt-brine slush. Such a slushy reservoir may be present on Enceladus and situated at the rock-ice interface below the south-pole region (Zolotov 2007).

\section{Water-Ice Interaction at High Pressure}

In large icy objects like Ganymede, Callisto, and Titan, high-pressure polymorphs of water ice, clathrate hydrates, and/or salts may have formed in the course of a satellite's thermochemical evolution. Seven stable phases of crystalline ice are known to exist at pressures and temperatures ranging between 0 and $2500 \mathrm{MPa}$ and from 200 to $350 \mathrm{~K}$, respectively. Among those, five phases melt to form liquid water upon heating and pressure release: ice Ih, ice III, ice V, ice VI, and ice VII. Ices Ic (cubic ice I) and ice II do not melt under these circumstances and are stable at lower temperature. These phases are the main focus of this section, adding to this panel the volatile-bearing clathrate hydrate phases and potential salts.

\subsection{Phase Diagram of $\mathrm{H}_{2} \mathrm{O}$-Rich Phases Under Pressure}

The phase diagram of $\mathrm{H}_{2} \mathrm{O}$ in the relevant range of conditions, as well as available experimental data on the stability of some major clathrate hydrate species, is shown in Fig. 1. Two principal thermal states of icy satellite interiors are distinguished, labeled 


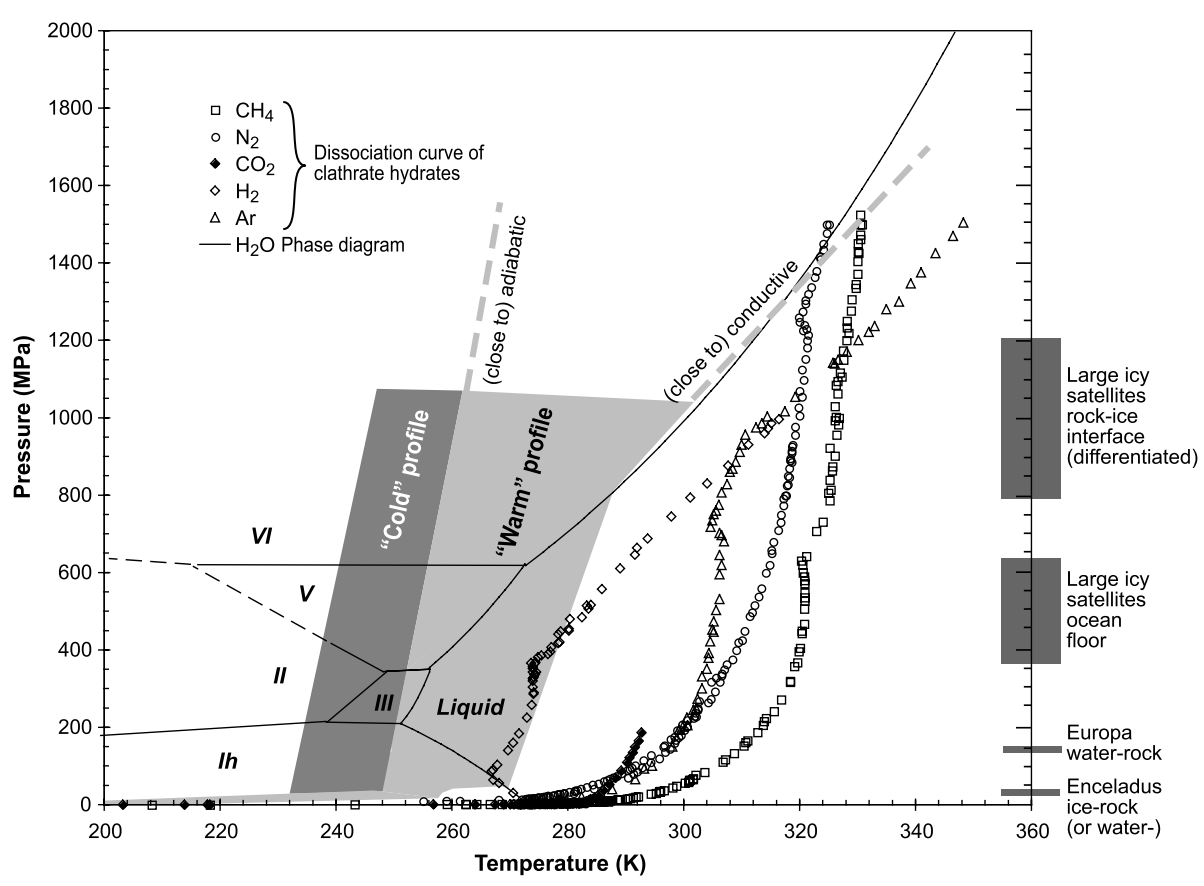

Fig. $1 P-T$ phase diagram showing the $\mathrm{H}_{2} \mathrm{O}$ ices relevant to icy satellite interiors (from Chizhov 1993 and Choukroun and Grasset 2007), and the dissociation curves of major clathrate hydrates under pressure (Sloan 1998, and references therein, Dyadin et al. 1997a, 1997b, 1997c, 2001, Manakov et al. 2001, 2004). For clathrate hydrates, solid-solid phase transitions under pressure are not specified to preserve legibility of the diagram. Ranges of possible thermal profiles within icy satellites, as well as the pressure (i.e. depth) of major interfaces, are indicated in grey

cold and warm. This distinction is based upon the presence or absence of an internal liquid layer. Whereas cold thermal states would require vigorous convection of icy mantles to efficiently compensate for internal heating a moon's interior, warm thermal states would result from less efficient conductive heat transfer in the presence of low conductivity icy phases at low temperature (from 0.5 to $6 \mathrm{~W} \mathrm{~m}^{-1} \mathrm{~K}^{-1}$ ) (see Hussmann et al. 2010; Schubert et al. 2010, this issue). For the sake of brevity, the phase diagrams of hydrated salts relevant to icy moons are not shown here (see Fortes and Choukroun 2010, this issue).

The phase diagram of Fig. 1 suggests that only the large icy satellites of Jupiter and Saturn may exhibit icy mantles deep enough to reach pressures above the ice Ih-ice II or ice Ih-ice III phase transitions. Yet, some mid-sized, ice-rich satellites of Saturn like Rhea may possess ice II or ice III in their deepest interiors, if the central part consists of an undifferentiated mixture of silicate and ice (Castillo-Rogez 2006; Anderson and Schubert 2007; Iess et al. 2007). In the case of Ganymede, Callisto, and Titan, it is likely that the present-day thermal profile intersects the high-pressure solid-liquid phase transitions, and that high-pressure ice polymorphs have allegedly formed (e.g. Lupo and Lewis 1979; Schubert et al. 1981, 1986).

A reliable description of ice melting relations as a function of pressure, i.e. depth, is a necessary tool for the prediction of the formation of high-pressure phases. The effect of impurities on melting relations is also of major importance. To that end, thermodynamic models have been developed to treat the pressure-dependent melting of planetary ices in a 
quantitative way (Chizhov and Nagornov 1990; Chizhov 1993; Wagner et al. 1994; Feistel and Wagner 2006; Choukroun and Grasset 2007). However, such models involve parameters that would require intense laboratory work and extrapolation to conditions beyond the range where experiments are conducted, occasionally leading to somewhat inaccurate results. On the other hand, Simon and Glatzel (1929) deduced a simple expression that facilitates a mathematical description of the melting curves. Two reference conditions are specified in the Simon-Glatzel equation, such as a triple point $\left(P_{0}, T_{0}\right)$ in the water ice phase diagram, together with two empirical constants, $a$ and $c$, derived from experimental data according to

$$
P=P_{0}+a\left[\left(\frac{T}{T_{0}}\right)^{c}-1\right]
$$

The corresponding parameters for the melting curves of ices Ih, III, V, and VI are summarized in Chizhov (1993), based on the experimental data of Bridgman (1912, 1937). Choukroun and Grasset (2007) have deduced new parameterizations of (3), also taking into account experimental work conducted by Henderson and Speedy (1987), Grasset (2001), Grasset et al. (2005). The usage of the Simon-Glatzel equation is limited in that it is only applicable to one-component systems, and cannot be used in a convenient manner to describe the melting of ices in a mixed system, like $\mathrm{H}_{2} \mathrm{O}-\mathrm{NH}_{3}, \mathrm{H}_{2} \mathrm{O}-\mathrm{MgSO}_{4}$, or other binary (and more) mixtures with a eutectic point. For such systems, the use of a thermodynamic and/or sophisticated numerical model approach is essential to accurately predict the melting surfaces in three-dimensional space given by pressure, temperature, and composition. The model developed by Grasset and Pargamin (2005) computes the effect of ammonia on the melting curves of ices, with application to Titan. Parameterization of the effect of salts containing major elements has been achieved by using a Pitzer method in the FREZCHEM software (Marion et al. 1999, 2010), with applications to Europa and Enceladus (Kargel et al. 2000; Zolotov 2007).

Another major type of icy solid that may be formed upon cooling of icy satellites is clathrate hydrates, in which a hydrogen-bonded $\mathrm{H}_{2} \mathrm{O}$ skeleton forms cages that trap guest molecules individually by weak van der Waals interactions (e.g. Sloan 1998, and references therein). Clathrate hydrates are thermodynamically more stable than water ice at pressures above a few MPa because of relatively steep gradients $d T / d P$ of the related phase stability curves. As shown in Fig. 1, most planetary-relevant gases with molecular diameters of less than $6 \AA$ can form clathrate hydrates. In terms of absolute pressure, the phase diagram suggests that most clathrate hydrates of these gases are thermodynamically stable within icy satellites. However, one misleading property of gas hydrates is that their stability is governed by the partial pressure of the guest gas, rather than the absolute pressure. Furthermore, their ability to form from a mixture of liquid water and dissolved gas, or to dissociate, is also dependent upon the amounts of gas that can be present, i.e. it is closely related to the solubility of the gas at given ambient conditions.

One must bear in mind these peculiarities, as it implies that some clathrates would not be present, though otherwise suggested by their phase diagrams. Let us use the example of $\mathrm{CH}_{4}$ clathrates to illustrate this issue. Numerous data have been obtained on the $\mathrm{H}_{2} \mathrm{O}-\mathrm{CH}_{4}$ system (see Sloan 1998, and references therein), which clearly establish the high stability of methane clathrates under pressure. In all these studies, the amounts of methane were somewhat close to the ideal formula of methane clathrates, that is $\left(\mathrm{CH}_{4} \cdot 5.75 \mathrm{H}_{2} \mathrm{O}\right)$. Choukroun et al. (2010) have shown experimentally that, in an aqueous system that contains $0.1 \mathrm{wt} \%$ of $\mathrm{CH}_{4}$ or less, the dissociation curve under pressure reaches a maximum temperature of 275$280 \mathrm{~K}$, which is $45-50 \mathrm{~K}$ lower than the dissociation temperature suggested by the previous 
Fig. 2 Specific volume of melted phases of $\mathrm{H}_{2} \mathrm{O}$ as a function of pressure. Available experimental data on the specific volume of ices are derived from the measurements of Bridgman (1912, 1937) along the melting curves. $\mathrm{TP}_{i}(i=1,2,3)$ refer to the triple points in the $\mathrm{H}_{2} \mathrm{O}$ phase diagram: 1 for Ih-III-L (Liquid), 2 for III-V-L, and 3 for V-VI-L.

The specific volume of $\mathrm{H}_{2} \mathrm{O}$ has been calculated at $280 \mathrm{~K}$,

following the model of

Choukroun and Grasset (2007).

Reprinted with permission from Choukroun and Grasset (2007). Copyright 2007, American Institute of Physics

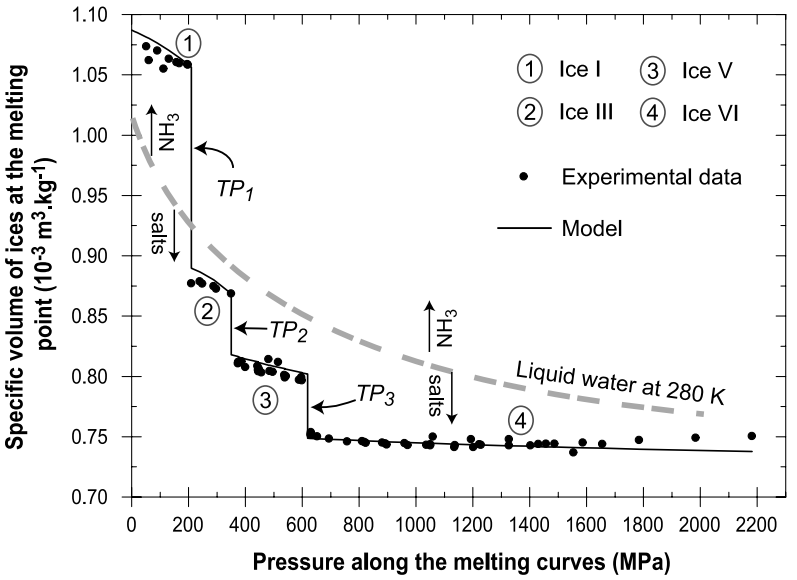

Pressure along the melting curves (MPa)

experimental data. This result is consistent with thermodynamic predictions using the model of Sloan (1998) with the fugacity laws from Duan et al. (1992), and is valid for any given clathrate hydrate. Therefore, for abundant gaseous species on icy bodies such as $\mathrm{CH}_{4}, \mathrm{CO}_{2}$, and $\mathrm{N}_{2}$, the formation of clathrate hydrates seems to be a process that needs accounting for in geophysical models. However, $\mathrm{CO}_{2}$ may escape clathration due to conversion to bicarbonate and carbonate ions in oceanic water. If formed, $\mathrm{N}_{2}$ and $\mathrm{H}_{2}$ are poorly soluble and could have escaped from satellites (Zolotov and Shock 2004). Further, it is still uncertain if minor species like noble gases are able to form clathrates in icy bodies.

\subsection{Density and Segregation of Materials}

Using phase diagrams, we are able to predict the type of solid phases that may form at the bottom of the ocean, either by solidification upon cooling (ices, clathrates) or by chemical reaction with the silicate interior (minerals). The implications of these phases at the level of a whole icy satellite then depends on: (i) where they will be preferentially located, and (ii) how they will influence heat transfer, hence the dynamics. The buoyancy of the solid phases relative to the liquid layer is the main property controlling the distribution of these phases. Buoyancy thus depends on the respective density of the phases, or their specific volume (which is the inverse of density).

The density of pure liquid water is well known in the temperature and pressure ranges of 298-373 K and 0-800 MPa, respectively (e.g. Grindley and Lind 1971). Several equations of state reproduce accurately these data (e.g. Minassian et al. 1981; Choukroun and Grasset 2007). The work of Bridgman (1912, 1937) provides phase transition data on water ices as well as associated variations in thermodynamic properties, including sudden changes in specific volume. Their experimental data are reproduced with variable accuracy by a number of numerical simulations (Chizhov and Nagornov 1990; Chizhov 1993; Tchijov et al. 2004; Choukroun and Grasset 2007). Figure 2 shows the specific volume of the solid phases of $\mathrm{H}_{2} \mathrm{O}$ along their melting curves, as a function of pressure, and compares it to the specific volume of pure liquid water at $\sim 280 \mathrm{~K}$.

High-pressure phases of ice are $\sim 5-15 \%$ denser than liquid water close to the melting point, therefore they would sink to the bottom of the liquid layer upon crystallization. Given both the large density contrast between consecutive ice phases and the likely slow cooling 
Table 1 Typical densities of some clathrate hydrates at $\sim 5-10 \mathrm{MPa}$ and $\sim 280 \mathrm{~K}$ for partial and full cage occupancy. Partial occupancy considered is 0.7 and 0.9 for small and large cages, respectively. After Sloan (1998)

\begin{tabular}{llll}
\hline $\begin{array}{l}\text { Guest } \\
\text { gas }\end{array}$ & Structure & $\begin{array}{l}\text { Density, } \mathrm{kg} \mathrm{m}^{-3} \\
\text { partial occupancy }\end{array}$ & $\begin{array}{l}\text { Density, } \mathrm{kg} \mathrm{m}^{-3} \\
\text { full occupancy }\end{array}$ \\
\hline $\mathrm{CH}_{4}$ & sI & 901 & 920 \\
$\mathrm{~N}_{2}$ & sII & 951 & 1001 \\
$\mathrm{CO}_{2}$ & sI & 1084 & 1134 \\
$\mathrm{Ar}$ & sII & 1021 & 1093 \\
$\mathrm{Kr}$ & sII & 1280 & 1430 \\
$\mathrm{Xe}$ & sI & 1654 & 1805 \\
\hline
\end{tabular}

rate of the liquid layer, it is expected that the layer of high-pressure ices is stratified, with ice VI overlaying the silicate core (if the transition to the rocky core is at pressures above $620 \mathrm{MPa}$ ), and ice $\mathrm{V}$ above it. Finally, on the cold side of the range of thermal profiles in Fig. 1, ice III may segregate into a thin layer as well. During this sequence of crystallization/segregation of high-pressure ices, the liquid layer is expected to remain located right beneath the outer ice Ih layer (ice Ih being the least dense crystalline $\mathrm{H}_{2} \mathrm{O}$ phase).

This scenario, though based on the quantitative comparison shown in Fig. 2, does not take into account the effect of dissolved species on the density of the liquid layer. Dissolved species may affect the density in two ways, since they involve not only ions and neutral species (including organic species), which would increase the density of aqueous solutions, but also gases, whose solubility in liquid water generally increases with pressure, leading to a decrease in the bulk density. Overall, the changes in density associated to the dissolution of gaseous compounds are negligible compared to the large difference in specific volume between solid and liquid water phases. Therefore, we consider the effect of crystallization of clathrate hydrates of these gases. Depending on the type of clathrate hydrate that forms, and the occupancy of the cages, the density can vary significantly as shown in Table 1 for some major clathrate hydrates expected within icy satellites. Since the bulk moduli of water ice phases and those of clathrate hydrates are similar ( $\sim 9 \mathrm{GPa}$ for ice, $\sim 7-8 \mathrm{GPa}$ for clathrate hydrates, e.g. Sloan 1998), the density comparison at low pressure is allegedly valid at high pressures as well, despite the lack of experimental data. The density of ice Ih is of $920 \mathrm{~kg} \mathrm{~m}^{-3}$ at that pressure, that of liquid water $\sim 1050 \mathrm{~kg} \mathrm{~m}^{-3}$. In comparison, only $\mathrm{CH}_{4}$ and $\mathrm{N}_{2}$ clathrate hydrates are less dense if the cages are fully occupied. Pure Ar clathrates may be less dense in the case of partial occupancies, but unless large amounts of Ar are present, these clathrate hydrates should not be stable within icy satellites. If one considers a mixed gas-water system, it appears that clathrate hydrates containing large amounts of methane will tend to be less dense than the liquid layer and thus float beneath the outer ice layer, as may have happened on Titan (Tobie et al. 2006; Lunine et al. 2009), whereas $\mathrm{CH}_{4}$ poor clathrates will tend to sink to the bottom of the liquid layer and thicken the solid layer (Prieto-Ballesteros et al. 2005).

The effect of other compounds on the density of the liquid is much more complex, and it is shown qualitatively by the arrows in Fig. 2. For example, the density of a saturated $\mathrm{MgSO}_{4}$ aqueous solution is around $1200 \mathrm{~kg} \mathrm{~m}^{-3}$, i.e. about as dense as the ice III polymorph. Aqueous ammonia, on top of its notorious anti-freeze effect, decreases the density of the solution: a near-eutectic $\left(34 \% \mathrm{NH}_{3}\right.$ ) composition is less dense than water ice, $920 \mathrm{~kg} \mathrm{~m}^{-3}$, at temperatures higher than $230 \mathrm{~K}$ (Croft et al. 1988). One must bear in mind that the concentration of solutes likely remains below 5 to $10 \%$ (see Sect. 2 in application to Europa), and therefore the possible shift of the liquid density curve shown in Fig. 2 should not exceed $\sim 50 \mathrm{~kg} \mathrm{~m}^{-3}$, i.e. $2 \times 10^{-5} \mathrm{~m}^{3} \mathrm{~kg}^{-1}$ if expressed in units of specific volume. This corresponds roughly to 
the length of the arrows indicating the effect of salts and of ammonia on liquid density. For this reason, ammonia-water solutions have long been inferred as best candidates for driving cryovolcanic eruptions in the outer solar system. As to the high-pressure phases, the presence of $\mathrm{NH}_{3}$ will tend to decrease the thickness of the icy layers at depth due to its anti-freeze action (e.g. Sohl et al. 2003), but it is not expected to modify qualitatively the organization of these layers since $\mathrm{NH}_{3}$ does not enter the crystalline structure of ices. Conversely, solutes $\left(\mathrm{Cl}^{-}, \mathrm{HCO}_{3}^{-}, \mathrm{SO}_{4}^{2-}, \mathrm{Na}^{+}, \mathrm{Ca}^{2+}, \mathrm{Mg}^{2+}\right.$, etc. $)$ will increase the density of the liquid phase. These ions also deplete the melting point of ices, though to a lesser extent than ammonia or methanol (see Fortes and Choukroun 2010, this issue, and references therein).

This is also likely to apply for sodium chloride and putative ammonium sulfate solutions. One might expect this peculiarity to result in a different segregation of the ices, with ice III tending to float to the top of the liquid rather than towards the bottom. Eventually, upon freezing of a substantial amount of oceanic water, numerous hydrated salts would precipitate from the aqueous solution. Overall, at standard temperature and pressure conditions (i.e. $\sim 10^{5} \mathrm{~Pa}$ and $298 \mathrm{~K}$ ), these salts have densities that fall within the range from $1400 \mathrm{~kg} \mathrm{~m}^{-3}$ $\left(\mathrm{Na}_{2} \mathrm{SO}_{4} \cdot 10 \mathrm{H}_{2} \mathrm{O}\right)$ to $1750 \mathrm{~kg} \mathrm{~m}^{-3}\left(\left(\mathrm{NH}_{4}\right)_{2} \mathrm{SO}_{4}\right)$. Upon crystallization from a saturated or supersaturated solution that may represent an icy satellites ocean in a late stage of freezing, they would be expected to sink to the bottom and enrich the solid layer on the ocean floor (Zolotov 2007). As several phase transitions of hydrates have been reported in the $\mathrm{H}_{2} \mathrm{O}$ $\mathrm{MgSO}_{4}$ and the $\mathrm{H}_{2} \mathrm{O}-\mathrm{NH}_{3}$ systems (see Fortes and Choukroun 2010, this issue), some highpressure phases of those systems may form as well.

\section{Physical Aspects of Water-Rock Interaction}

On small ocean-bearing icy satellites where the ocean is in contact with silicate rock below, water-rock interactions would affect heat dissipation, oceanic composition, and the mineralogy of rocks and oceanic sediments. Earth hosts a diversity of water-rock systems, broadly referred to as hydrothermal, which advectively transport geothermal heat concentrated by magma emplacement in direct proximity (km-scale; i.e. dikes) or farther away (e.g. hotspots). Whereas seafloor spreading caused by mantle convection is the main driver for terrestrial hydrothermal activity on Earth (Sclater et al. 1980), hotspot volcanism might be sufficient to advect heat from deep rocky interiors of icy satellites if magmatic activity prevails. Note, however, that hydrothermal activity can also occur in the absence of magmatic activity.

\subsection{Permeability of Ocean Floor Rock}

The abundance and distribution of hydrothermal systems in an icy satellite seafloor can be estimated by applying estimates for Earth to heat flow, temperature and gravity appropriate. The exercise, as applied to Europa, highlights the importance and uncertainty of permeability. Estimates of permeability in hydrothermal systems may span a range from $10^{-17}$ to $10^{-9} \mathrm{~m}^{2}$ (Fisher 1998). At mid-ocean ridges on Earth and in other places where tectonic activity opens large flow channels in the seafloor, models of flow through hydrothermal systems constrain permeability to around $10^{-12} \mathrm{~m}^{2}$ (Fisher 1998; Fisher and Becker 2000; Becker 2000). Moving away from mid-ocean ridges, permeability decreases to $10^{-17} \mathrm{~m}^{2}$ in older (age 65-200 Myr) seafloor basalt (Stein et al. 1995; Sinha and Evans 2004).

The permeability of Earth's seafloor may diminish over time due to filling of pore spaces, either by silica and other secondary minerals that precipitates from ambient fluid (Stein et al. 
1995), or by the accumulation of sediments (Martin and Lowell 2000). Laboratory (Martin and Fyfe 1970; Zimmerman et al. 1986) and bore-hole investigations (Anderson et al. 1985) to $\sim 1 \mathrm{~km}$ depth in Earth's lithosphere indicate high temperatures and pressures tend to close pore spaces. See Wash and Brice (1984) for a discussion of the effect of pressure on porosity and transport properties of rock. In small bodies like Enceladus, where central pressures approach a mere $20 \mathrm{MPa}$, and where the presence of ammonia may create temperatures of aqueous solutions as low as $\sim 180 \mathrm{~K}$, rock permeabilities could be much higher than those in Earth's oceanic crust. The greater depth extent of permeable rocks on small, less massive satellites is due to low internal pressure as a consequence of their lower gravitational acceleration at the surface. In deep oceans like Europa's, where average pressure at the ocean floor is $\sim 2-7$ times the average in Earth's oceans (Anderson et al. 1998). Rocks become impermeable when subjected to pressures exceeding about $300 \mathrm{MPa}$ (Wash and Brice 1984). This critical pressure is about twice as high as that expected at Europa's ocean floor and suggests that a $\sim 20$ to $30 \mathrm{~km}$ thick rock layer of non-vanishing permeability may exist below the seafloor of Europa's ocean.

In regions of ocean-ridge systems where fracture-induced large-scale permeability is absent, water is expected to percolate through microfracture channels to greater depth (Lister 1974; Sinha and Evans 2004). The depth to which microfractures form may serve as an upper limit for the depth of water-rock interaction. Vance et al. (2007) adopt a model for the thermally-induced formation of microfractures controlled by the development of residual stresses at grain boundaries. In a cooling rock, anisotropic thermal stresses will increase along grain boundaries. At high temperatures, residual stresses dissipate via viscous creep processes and cracking is inhibited. At low temperatures, where dissipative processes are sluggish, residual stresses accumulate along grain boundaries. Two-layer conductive thermal models for candidate ocean worlds are used to estimate fracture formation depth from the calculated pressure and temperature at which microfracture formation ceases. For the smallest objects considered, Ceres and Enceladus, the water percolation depth would be greater than $100 \mathrm{~km}$, nearly four times that expected for Europa's ocean floor. In all objects considered, the rate of exposure of new rock is one to ten thousand times slower than present rates of seafloor spreading on Earth $\left(45 \mathrm{~mm} \mathrm{yr}^{-1}\right)$. For differentiated ocean-bearing bodies exceeding Triton in size, cracking is inhibited since ocean floor pressure would be much too high. For Enceladus, fluid access is predicted to occur to the deepest interior in the earliest period. Water-rock interactions may continue to the present in Enceladus where low-temperatures limit reaction rates, or if tidal processes cause episodic aqueous alteration of the interior. Also notable is the effect of diminished internal heating on the depth of cracking. Where cooling rate, grain size and composition are identical to those for the regions of Earth's ocean floor under consideration, fluid circulation is predicted to occur to orders of magnitude greater depth. Revised depths of fluid circulation would change previous estimates of the biopotential of extraterrestrial lithospheres (Vance et al. 2007).

\subsection{Tidally-Induced Porous Flow and Hydrothermalism}

Tidal interaction between a satellite and its primary (see Hussmann et al. 2010, this issue) is relevant to the satellite's ocean-rock interface in two ways: (i) dissipation of tidal energy due to frictional losses in the body tide and ocean bottom friction (see Sohl et al. 1995, and references therein), (ii) the ice shell and the ocean below follow the equilibrium tide by adjusting to the time-variable tidal bulge, thereby inducing pressure changes at the seafloor because of the related mass loading (see Vance et al. 2007, and references therein). The first of these can in some cases contribute significantly to the satellite's energy budget (see 


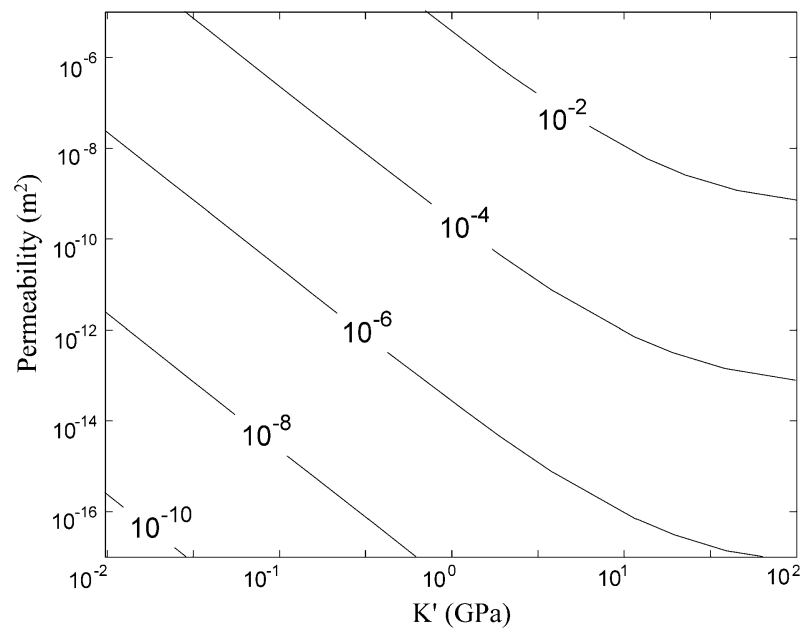

Fig. 3 Contoured rates of tidal energy release (in units of $\mathrm{W} \mathrm{m}^{-2}$ ) due to frictional losses in the near subsurface of Europa's ocean floor. Contours are shown as a function of permeability and confined bulk modulus of the rock matrix $K^{\prime}$ for an ocean floor porosity of $n=0.1$, consistent with drill hole measurements in the uppermost kilometer of Earth's oceanic crust (Becker et al. 1982). The tidal height is fixed at $u_{r}=27.4 \mathrm{~m}$, corresponding to locales near the sub- and anti-Jovian point, respectively. Reprinted with permission from Vance et al. (2007). Copyright 2007, Mary Ann Liebert, Inc

below). The latter process generates only modest heating for generous estimates of rock porosity. However, tidally enhanced fluid flows may be important where thermal gradients are not steep enough to drive vigorous convection.

The local height of the tidal bulge is given by the ratio between the primary tidal potential and the gravitational acceleration at the surface. In-situ tide gauge data and deepocean bottom pressure gauge data are routinely collected on Earth and support the view that tidally-induced ocean bottom pressure variations are caused by the tidal load of the ocean and deformation of the seafloor due to body and the ocean tides. As a consequence, the tidal forcing of the ice shell covering the water ocean below may act as a time-variable hydrostatic head. The incremental stress induced by the corresponding ocean bottom pressure variations would be partitioned between the rock matrix and interstitial pore water. Provided the seafloor rock were fractured, ocean water could readily move in response to the tidallyinduced loading, thereby causing dissipation of tidal energy due to frictional losses. As detailed in Vance et al. (2007), the corresponding tidal energy release would depend on the mechanical properties of the fluid and the rock matrix, the tidal period, and the magnitude of tidal distortion of an ocean-bearing body.

The tidal energy dissipated is proportional to the product of the Darcy flow velocity through a porous matrix times the pressure gradient. The pore pressure change below the seafloor is governed by the periodic loading due to the tide and the elastic properties of the ocean floor material. Details of models and parameter that are taken to be commensurate with Earth's values are described in Wang et al. (1999) and Vance et al. (2007). Figure 3 illustrates how tidally-induced dissipation rates per unit area on Europa will depend on ocean floor permeability and bulk modulus of the rock matrix. Heating due to frictional losses is on the order of $0.001-1 \mathrm{~mW} \mathrm{~m}^{-2}$, if the bulk modulus is fixed at $10 \mathrm{GPa}$ and permeability would range from $10^{-17}$ to $10^{-9} \mathrm{~m}^{2}$. Additionally, heat generation would vary by roughly one order of magnitude in the likely range of porosities between 0.1 to 0.5 . Finally, assum- 


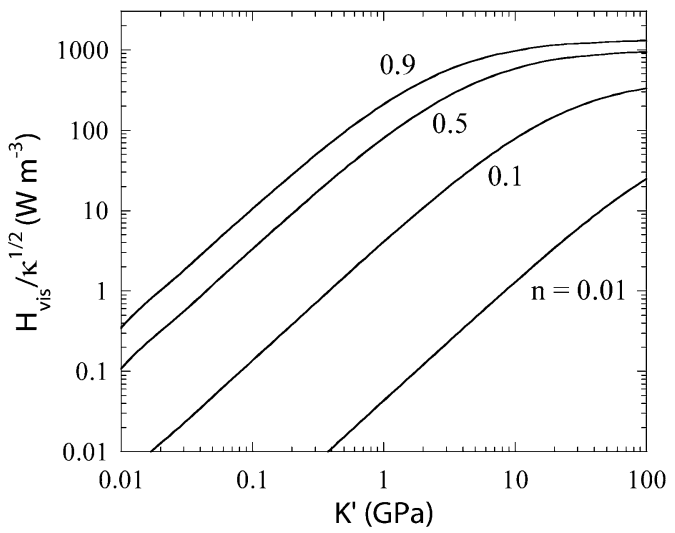

Fig. 4 Rate of tidal energy release normalized to permeability $H_{v i s}$ (in units of $\mathrm{W} \mathrm{m}^{-3}$ ) as a function of confined bulk modulus of the rock matrix $K^{\prime}$ in the near subsurface of Europa's ocean floor. Curve labels denote ocean floor porosities ranging between $0.01<n<0.9$. The tidal height is fixed at $u_{r}=27.4 \mathrm{~m}$, corresponding to locales near the sub- and anti-Jovian point, respectively. Reprinted with permission from Vance et al. (2007). Copyright 2007, Mary Ann Liebert, Inc

ing these material properties for potential ocean-bearing bodies, this heating mechanism is deemed significant only on Europa (Fig. 4) because tidal bulge heights on other satellites are relatively small compared to Europa's (see Hussmann et al. 2010, this issue). Where interfaces separate vertical seafloor layers with different bulk moduli, additional porous flow is induced by the difference in instantaneous response of the pore pressure across the interfaces. If the seafloor has multiple-layered structure with different bulk moduli, the amplitude of generated heat may become several times larger (Wang et al. 1999). The present discussion illustrates the potential importance of dissipation of tidal energy as a localized heat source in the near subsurface of Europa's ocean floor.

\subsection{Serpentinization of Ocean Floor Rock}

At the off-axis mid-Atlantic hydrothermal systems Trans-Atlantic Geotraverse (TAG), Rainbow, and Lost City, the geological process of serpentinization provides a significant source of thermal energy. In the Lost City system, it is likely that serpentinization constitutes the dominant thermal energy source (Kelley et al. 2005). Water-rock interactions on icy bodies imply the potential for serpentinization processes in extraterrestrial oceans lacking midocean-ridge tectonics, with implications for astrobiology.

Ferromagnesian silicate minerals are dominant in unfractionated igneous rocks (e.g. peridotites) that comprise Earth's upper mantle, and may typify subseafloor lithologies on small ocean planets. The abundance of peridotite in a planetary lithosphere is largely governed by the temperature of formation, which depends on the timing of formation relative to the body's ability to dissipate heat (Schubert et al. 1986; McKinnon and Zolensky 2003). Even later, slower radiogenic heating can be intense enough to form peridotite, but eventually cooling takes over and the system turns retrograde — at lower temperatures, thermodynamic disequilibrium favors a transformation to the hydrated mineral form, in this case serpentine. In the event of an early period of peridotite-forming intense heating, the subsequent formation of ocean(s) could give rise to an epoch of serpentinization-driven hydrothermal activity. 
An estimate of the heat generated by serpentinization can be obtained by considering the energy released in hydrating available material in the volume of rock to depth $z$ below the seafloor. Estimates of heating for presently known and candidate ocean planets are reported by Vance et al. (2007), considering the hydration of the Mg-end member of olivine,

$$
\begin{aligned}
& 2 \mathrm{Mg}_{2} \mathrm{SiO}_{4}+3 \mathrm{H}_{2} \mathrm{O} \leftrightarrow \mathrm{Mg}(\mathrm{OH})_{2}+\mathrm{Mg}_{3} \mathrm{Si}_{2} \mathrm{O}_{5}(\mathrm{OH})_{4}, \\
& \text { forsterite }+ \text { water } \leftrightarrow \text { brucite }+ \text { serpentine. }
\end{aligned}
$$

For simplicity an average enthalpy of reaction of $\Delta H=-83 \mathrm{~kJ}$ per mol serpentine is assumed. Bulk composition is assumed to be lherzolitic, consistent with Earth's primordial mantle: $70 \%$ olivine, with an Fe/Mg ratio of 0.1 . All of the olivine is assumed to hydrate into serpentine and brucite. Under these assumptions, present-day heating due to serpentinization would comprise less than a percent of radiogenic heating for all bodies considered. However, the slow release of this form of energy allows it to sustain gradients in chemical potential over long periods of time. These factors make even minor amounts of serpentinization important when assessing the habitable potential of icy satellites.

\section{Comparison Between Icy Bodies}

Henceforth, a thick layer of hydrated compounds can form beneath the putative liquid layer of icy satellites, with a wide range of compositions: from high-pressure phases of ices, to salts, and clathrate hydrates. The composition depends on the physical conditions (pressure, temperature) of the ocean floor and their evolution through time, and on the chemical evolution. As a consequence, a number of icy satellites of Jupiter or Saturn likely has an ocean floor with characteristics of its own. This means that, despite similar bulk characteristics, large icy satellites such as Titan, Ganymede, and Callisto may exhibit different internal structures.

\subsection{Europa: Sulfates, Sulfides, and Prolonged Water-Rock Interaction}

Europa's interior is thought to be fully differentiated into a metallic core, silicate mantle, and outer water ice/liquid shell, as inferred from measurements of the Galileo spacecraft of the satellite's density, low-degree gravitational field, and shape (e.g. Schubert et al. 2009). The satellite's induced magnetic field further suggests the presence of a global sub-surface liquid water ocean within Europa's outer ice shell, probably enriched in dissolved salts. The thickness of the ice Ih shell has been estimated between 1 and a few tens of kilometers from several types of measurements and models (Billings and Kattenhorn 2005, and references therein). The Galileo mission has also supplied numerous pieces of evidence for a geologically young surface, with tectonics processes, and compositional heterogeneities such as hydrated sulfate-bearing compounds, some of which appear to originate from the internal liquid layer (e.g. McCord et al. 1999; Pappalardo et al. 1999; Carlson et al. 1999).

In a differentiated Europa model, the internal ocean layer is approximately $100 \mathrm{~km}$ thick (Anderson et al. 1998; Sohl et al. 2002; Schubert et al. 2004; Kuskov and Kronrod 2005), owing to a high mean density $\left(3010 \mathrm{~kg} \mathrm{~m}^{-3}\right)$ that implies a rocky or silicate-metal-sulfide interior of up to $90 \%$ of the satellites mass. The transition pressure between the ocean and the rocky interior is around 130-150 MPa, given the ocean thickness and density, and a gravity of $1.314 \mathrm{~m} \mathrm{~s}^{-2}$. This pressure is lower than those of the ice Ih-ice II or ice Ih-ice III 
transition, so no high-pressure phases of ice should form. Water-rock interaction could have led to hydration (e.g. serpentinization) and oxidation of rocks and organic materials leading to the production of $\mathrm{H}_{2}, \mathrm{~N}_{2}$, and $\mathrm{CO}_{2}$ (e.g. Zolotov and Kargel 2009, and Sect. 2). The formation of sulfates could have involved elevated temperatures $\left(\gtrsim 200^{\circ} \mathrm{C}\right)$ and $\mathrm{H}_{2}$ escape (Zolotov and Shock 2004). Most clathrate hydrate species are thermodynamically stable, but the amount of gas available are likely a limiting factor in their formation. Dense hydrated salts and $\mathrm{CH}_{4}$-poor clathrate hydrates (see Sect. 3) may form at those conditions and gather as a solid layer at the interface (Kargel et al. 2000; Prieto-Ballesteros et al. 2005). Such a barrier would have an insulating effect on the silicate portion of the interior, because of the low thermal conductivity of these materials (ranging between 0.5 and $2.5 \mathrm{~W} \mathrm{~m}^{-1} \mathrm{~K}^{-1}$ for clathrates and salt hydrates, respectively).

The composition of Europa's tenuous atmosphere and non-ice surface materials may imply the presence of $\mathrm{MgSO}_{4}, \mathrm{Na}_{2} \mathrm{SO}_{4}$, and $\mathrm{H}_{2} \mathrm{SO}_{4}$ hydrates among other species $\left(\mathrm{H}_{2} \mathrm{O}_{2}, \mathrm{O}_{2}\right.$, $\mathrm{CO}_{2}, \mathrm{SO}_{3}, \mathrm{~S}$ compounds), hydrated salts and gases trapped in the satellite's icy shell (Carlson et al. 2009). The seafloor rock and sediments could contain phyllosilicates, carbonates, Ca sulfates, Fe sulfides, and organic compounds (Zolotov and Kargel 2009). As detailed in Sect. 2, the chemical evolution of Europa's subsurface ocean and alteration of the seafloor are governed by water-rock interactions and hydrogen escape.

Kargel et al. (2000) proposed a model of a near-peritectic $\mathrm{H}_{2} \mathrm{O}-\mathrm{MgSO}_{4}$ composition of the Europan ocean, which would explain the presence of hydrated sulfates in the icy crust. Spaun and Head (2001) modeled the evolution of this ocean as a follow-up, and suggested that at present the $130 \mathrm{~km}$-thick icy crust may consist of ice $\mathrm{Ih}+/-$ meridianiite $\left(\mathrm{MgSO}_{4}\right.$. $11 \mathrm{H}_{2} \mathrm{O}$ ), overlying a meridianiite layer. That layer would be separated from the silicate portion by a 35-km thick layer of epsomite $\left(\mathrm{MgSO}_{4} \cdot 7 \mathrm{H}_{2} \mathrm{O}\right)$. In their model, no ocean would have been sustained until present, but they used a stationary model without accounting for potentially large tidal heating (e.g. Sotin et al. 2002; Tobie et al. 2003). Other chemical models such as those of Zolotov and Shock (2001) and of McKinnon and Zolensky (2003) suggest lower amounts of dissolved magnesium and sodium sulfates, which would result in a thinner layer of salts at the bottom of the ocean, if any. McKinnon and Zolensky (2003), based on the reduced state of sulfur in some chondrites and the low abundance of sulfates, argued that a km-thick sulfide-rich layer at the ocean seafloor is likely to be present while sulfates would remain in solution.

Depending on the redox conditions, clathrates containing a mixture of $\mathrm{CO}_{2}$ and $\mathrm{SO}_{2}$ or $\mathrm{CH}_{4}$ may have formed at the water-rock interface (e.g. Kargel et al. 2000; Prieto-Ballesteros et al. 2005), and might have migrated upwards if the liquid layer was enriched in dissolved salts and thus denser than the clathrates. Conversely, in a dilute ocean model, i.e. $<10 \mathrm{wt} . \%$ sulfates, clathrates would have formed an insulating layer at the bottom of the ocean because of a negative buoyancy contrast. In terms of planetary evolution, the mere existence of this insulating layer would have a dramatic influence: (i) it would make a mechanically decoupling barrier, precluding further ocean-rock interactions unless cracking occurs; (ii) it would allow a hotter silicate interior and a colder liquid layer, which would then tend to solidify further. Clay minerals, sulfur, and organic compounds could also play a role in insolating silicate mantle rocks from oceanic water. Finally, significant volume expansion of suboceanic rocks through hydration (e.g. serpentinization) would considerably decrease their porosity and permeability. The extent of these influences would depend on the nature and properties (density, thermal conductivity) of the phases that crystallize, as well as on the thickness of the insulating layer.

Europa, as an intermediate-sized object undergoing tidal heating, may constitute a rare example of an icy world with extensive and prolonged water-rock interaction. In the twentyfirst century, a continuing program of missions to the outer solar system, with increasingly 
Fig. 5 Radial distribution of density for three core compositions of Ganymede. From top to bottom: pure Fe; Fe-FeS (50:50 by wt.); pure FeS core. Modified from Sohl et al. (2002)

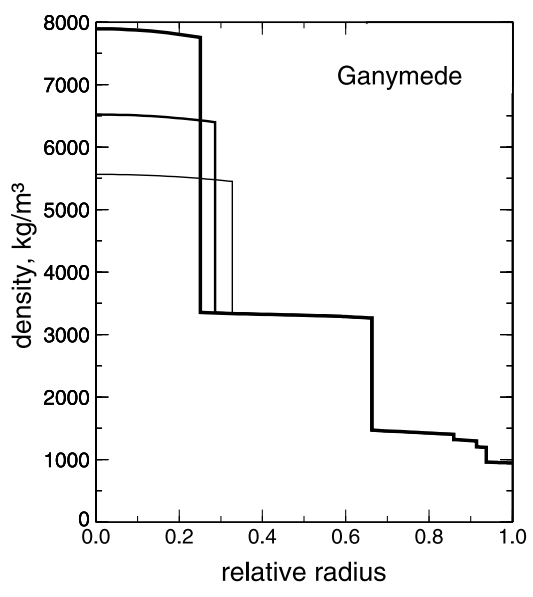

global participation, promises to shed light on water-rock interactions in ocean-bearing icy bodies.

\subsection{Ganymede, Callisto, and Titan: Ammonia and Icy Seafloors}

The outer two Galilean satellites and the largest moon of Saturn have characteristics in common: (i) their mean density, $1881 \mathrm{~kg} \mathrm{~m}^{-3}$ for Titan, $1940 \mathrm{~kg} \mathrm{~m}^{-3}$ for Ganymede, and $1851 \mathrm{~kg} \mathrm{~m}^{-3}$ for Callisto, and (ii) their radius, 2575, 2634 and $2403 \mathrm{~km}$, respectively, are in the same order. This implies that they bear a similar rock mass fraction on the order of 50 wt.\%. Gravity data from the Galileo mission (e.g. Schubert et al. 2004) and new results from the Radio Science experiment onboard the Cassini spacecraft (Iess et al. 2010) have shown that Ganymede is fully differentiated (Fig. 5), whereas the deep interiors of Titan and Callisto may partly contain an undifferentiated mixture of rock and ice. Ganymede's central mass concentration and self-sustained magnetic field strongly suggest the presence of an iron core (e.g. Anderson et al. 1996; Kivelson et al. 2004), whereas circumstantial evidence for the existence of a metallic core is lacking in the case of Titan. Therefore, some variability on the temperature and density stratification affects their interior. The thickness of the $\mathrm{H}_{2} \mathrm{O}$ mantle has been estimated to $600-1000 \mathrm{~km}$ for differentiated Ganymede (Kuskov and Kronrod 2001; Sohl et al. 2002) and tentatively differentiated Titan (Grasset et al. 2000; Sohl et al. 2003; Grasset and Pargamin 2005; Tobie et al. 2005b), corresponding to a pressure at the ice-rock transition of $\sim 0.8$ to $1.2 \mathrm{GPa}$. In the event of partial differentiation of Callisto, the transition from the $\mathrm{H}_{2} \mathrm{O}$-dominated outer layer to the rock-ice core below must be expected to occur at a depth of $300 \mathrm{~km}$ (Kuskov and Kronrod 2005) to $600 \mathrm{~km}$ (Sohl et al. 2002). The results obtained by Iess et al. (2010) suggest that Titan's state of internal differentiation is an intermediate between Callisto and Ganymede, indicating that satellites of similar size and composition in terms of their primordial ice-rock mixtures may display distinct degrees of internal differentiation (e.g. Sotin et al. 2009).

Thicknesses of the liquid and of the high-pressure ice layers at present would depend on the internal heat production rate, and on the presence of anti-freeze constituents in the liquid layer. Of particular relevance to Titan is $\mathrm{NH}_{3}$, which could be the source of the current atmospheric $\mathrm{N}_{2}$ (Atreya et al. 1978; Niemann et al. 2005), and also a cryomagma component candidate that would dissociate crustal methane clathrates and replenish the atmospheric 
methane (Tobie et al. 2006; Choukroun et al. 2010), continuously lost in photochemistry. From the calculation by Grasset and Pargamin (2005) of the thicknesses of the outer ice Ih and the internal liquid layers, it can be inferred that Titan's high-pressure ices layer is of 300$600 \mathrm{~km}$ to $400-700 \mathrm{~km}$, for 5 and $0 \mathrm{wt} . \%$ primordial $\mathrm{NH}_{3}$ in the $\mathrm{H}_{2} \mathrm{O}$ mantle, respectively. A similar thickness for the high-pressure ices layer can be expected on Ganymede, although its content at depth in ammonia and/or hydrated sulfates remains poorly constrained. Callisto may also have a high-pressure ice layer (Sohl et al. 2002), above the undifferentiated deep rock-ice interior. The thicknesses of the high-pressure ices layer within Ganymede and Titan are such that ice V and ice VI may be present therein. Within Callisto, the possible depth of $1700 \mathrm{~km}$ for the transition between the $\mathrm{H}_{2} \mathrm{O}$ outer shell and the undifferentiated deep rock-ice interior (Kuskov and Kronrod 2005) imply that ices V, VI, and possibly even VII, may exist.

It is possible to infer the thicknesses of the ice V and the ice VI sublayers on Ganymede and Titan, although this is a mere estimation because of: (i) the uncertainty in pressure at the interfaces; (ii) the difficulty to constrain a definite thermal profile, although the solidsolid phase transitions are roughly isothermal; (iii) the poor constraints on the presence and concentration of anti-freeze constituents; (iv) the imprecise knowledge of the effect of antifreeze constituents on the solid-solid phase transitions in $\mathrm{H}_{2} \mathrm{O}$ ice under pressure. Depending on the models, the pressure at the ocean bottom is ranging between 400 and $700 \mathrm{MPa}$, with 800-1200 MPa pressure at the bottom of the high-pressure ice layer. This pressure range corresponds to the 300-600 km thickness inferred above for this layer. A basic scaling thus suggests that the ice $\mathrm{V}$ sublayer is up to $\sim 150-200 \mathrm{~km}$ thick in a pure $\mathrm{H}_{2} \mathrm{O}$ model, while it may be less than $50 \mathrm{~km}$ thick in the presence of $5 \mathrm{wt} \% \mathrm{NH}_{3}$. The ice VI sublayer would occupy the remaining portion of the high-pressure solid layer, i.e. 200 to $400 \mathrm{~km}$, depending on the pressure of the interface and on the abundance of $\mathrm{NH}_{3}$ or another antifreeze constituent.

Fortes et al. (2007) have suggested that conversion of $\mathrm{NH}_{3}$ into $\mathrm{NH}_{4}^{+}$could have resulted in an $\left(\mathrm{NH}_{4}\right)_{2} \mathrm{SO}_{4}$-rich early ocean on Titan, which would have important implications for cryovolcanic processes. Grindrod et al. (2008) also studied the impact of a concentrated ammonium sulfate ocean on the interior structure of Titan. A corollary of this model is that these dense $\left(1780 \mathrm{~kg} \mathrm{~m}^{-3}\right)$ compounds may, upon precipitation from the liquid during cooling, contribute to some extent to the high-pressure phases layer. However, it should be noted that sulfates may not have formed on large satellites because of reducing conditions in the deep interior (see Sect. 2 of this paper). On Titan, the presence of $\mathrm{CH}_{4}$ suggests a relatively high $\mathrm{H}_{2}$ fugacity that would inhibit sulfate formation under those conditions, albeit the existence of sulfate salts at greater depth cannot be ruled out entirely.

\section{Discussion and Conclusions}

We have addressed lines of circumstantial evidence for the existence of present-day subsurface liquid water oceans on icy satellites. The ocean floor region on these moons may be the place of a wide range of exchange processes. Similarly to the Earth's oceans, where the liquid layer is directly in contact with the silicate interior, hydrothermal activity may occur, causing aqueous alteration of rocks. This is the expected situation within Europa (e.g. Zolotov and Kargel 2009) and Enceladus (e.g. Matson et al. 2007; Zolotov 2007). In large icy objects like Ganymede, Callisto, and Titan, high-pressure polymorphs of water ice, clathrate hydrates, and/or salts could have formed upon cooling.

Spacecraft observations, laboratory experiments, and theoretical modeling combined suggest that the existence and persistence of global subsurface liquid water oceans is 
strongly dependent on the subsurface structure, bulk composition, and coupled orbital and thermal history of an individual satellite (see Schubert et al. 2010, this issue). Four major sources of internal heat production governing the long-term thermal and chemical evolution following satellite formation can be identified: (i) radiogenic heating due to the silicate component by decay of long-lived radioactive isotopes; (ii) resonant orbital interaction between neighboring satellites and their primaries, resulting in the dissipation of tidal energy; (iii) heat of chemical reactions (e.g. hydration); (iv) latent heat release due to the crystallization of solids upon cooling. These internal and external heat sources will contribute in various extents to the total energy budget of icy moons with important implications for internal dynamics, surface tectonics and cryovolcanic resurfacing (see Hussmann et al. 2010, this issue).

Water ocean composition will be governed by the bulk ratios between rocks, water ice, non-water volatiles, and organic compounds, as well as thermal history. The silicate rock fraction incorporating long-lived radionuclides and the dissipation of tidal energy provide the dominant heat sources; the concentration of mass toward the center also affects the thermal state of the interior. Throughout history, the chemical evolution of subsurface liquid water oceans has been affected by the degree of ice melting, the extent and duration of chemical interactions between rocks and liquid water, degassing of the deep interior and oceanic water, freezing and re-melting, and secondary inorganic and organic precipitation. Pathways of subsequent oceanic evolution were mostly dependent on the scale, timing, and locations of heat production in the satellite interiors. Continuing heat production in rocky cores may have induced hydrothermal circulation in the rocky interiors, caused dehydration of previously formed minerals, and led to further alteration of organic matter. These processes suggest special conditions for water-rock interaction based on the size of an icy satellite, in the case of percolation depth, and its orbital configuration, in the case of tidallydriven circulation. Furthermore, bulk composition, degree and rate of internal differentiation of ocean-bearing bodies determine the extent of aqueous alteration (e.g. serpentinization). Subsurface water oceans are expected to have survived on larger icy bodies, e.g. the Jovian icy moons Europa, Ganymede, and Callisto, as well as Titan and Triton, due to diminished cooling and enhanced radiogenic heating compared to smaller icy bodies. However, depending on the individual amount of anti-freeze constituents, subsurface liquid water oceans in the largest mid-sized satellites of Saturn and Uranus cannot be entirely ruled out and may serve as analogues for the bulk structure of trans-Neptunian objects. On some of the latter, liquid water reservoirs beneath thermally isolating ice layers could have been maintained throughout their entire evolution (e.g. Hussmann et al. 2006; McKinnon et al. 2008; Desch et al. 2009).

Two extreme cases that may correspond to the ultimate stage of evolution of an internal liquid layer within icy satellites are compared in Fig. 6. These two scenarios are based on the distinction between cold and warm thermal profiles. The higher the salt/ammonia content of an icy satellite is, the colder the thermal profile across its interior should be.

First, consider an icy satellite subject to intense oxidation and hydration and enriched in salts, forming a thick bottom layer (from precipitation upon cooling). The latter would be thermally insulating and the predominant mode of heat transfer would be conduction (rather than advection of upwelling hot materials). This layer implies colder conditions above it, therefore a cooler ocean, enriched in salts, which would crystallize faster to balance the heat loss, forming an allegedly thick outer ice-Ih layer above a close-to-saturated ocean. This cold scenario may correspond to a class of models of Europa's interior involving ice and salt layers (Kargel et al. 2000; Spaun and Head 2001; Zolotov and Kargel 2009).

On the other hand, a dilute internal liquid layer containing salts and/or ammonia would be easily convective, transferring more heat to the outer regions, and releasing more heat as 


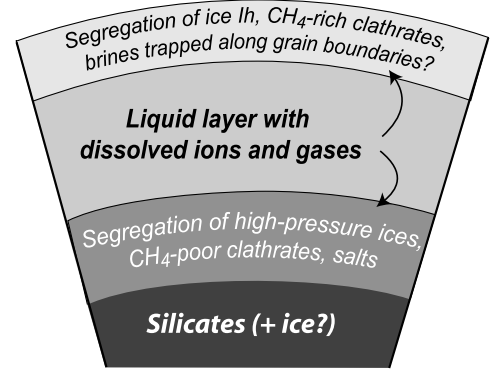

"Warm" model

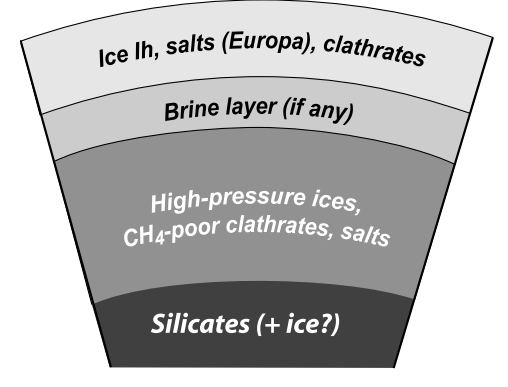

"Cold" model

Fig. 6 Two extreme interior structure models of icy satellites, depending on the amount of heat generated and non- $\mathrm{H}_{2} \mathrm{O}$ icy components. High-pressure ices can only be generated upon cooling of icy bodies with an $\mathrm{H}_{2} \mathrm{O}$ mantle larger than that of Europa. Beyond an increased thickness in layers of $\mathrm{H}_{2} \mathrm{O}$ ice, a cold model implies a higher concentration of soluble compounds in the liquid layer (if any remains), and a thicker layer of precipitated salts

ices crystallize. This more intense heat production and more efficient heat transfer would help maintain a warmer thermal profile. Furthermore, some hydrated salts and/or ammonia hydrates may crystallize lately in the evolution, or may form upon solidification of brine pockets trapped along grain boundaries in the outer ice-Ih layer. In the case of a large icy satellite, where the pressure at the bottom of the $\mathrm{H}_{2} \mathrm{O}$ mantle is above $200 \mathrm{MPa}$, highpressure ices would also have formed upon solidification of the ocean above. This warm scenario may represent the situation within Ganymede (e.g. Kuskov and Kronrod 2001; Sohl et al. 2002) and Titan (e.g. Grasset et al. 2000; Sohl et al. 2003; Tobie et al. 2005b). Provided the ice-Ih shell is subject to convection, trapped brine/ammonia pockets, representing only a small fraction of the outer ice shell, may be the driving source of resurfacing and outgassing by dissociation of clathrate hydrates (Choukroun et al. 2010). Given the current state of knowledge of the phase diagram of $\mathrm{MgSO}_{4}$ and other compounds, it is difficult to assess the temperature at which the hydrated salts would form. Therefore, whether the salts would form earlier or later than the high-pressure ices remains unconstrained. Further experimental data are required to address these issues.

In an object with an initially dilute internal liquid layer, the bulk composition would remain on the water-rich side of the eutectic in sulfate-, ammonia-, or chloride-bearing systems. If sulfates are present, a compound such as epsomite $\left(\mathrm{MgSO}_{4} \cdot 7 \mathrm{H}_{2} \mathrm{O}\right)$ is unlikely to exist at the bottom of the liquid layer, but the heavily hydrated phases such as meridianiite $\left(\mathrm{MgSO}_{4} \cdot 11 \mathrm{H}_{2} \mathrm{O}\right)$ and mirabilite $\left(\mathrm{Na}_{2} \mathrm{SO}_{4} \cdot 10 \mathrm{H}_{2} \mathrm{O}\right)$ might crystallize and form a layer on the ocean floor upon advanced freezing. A liquid layer with this kind of composition would either stay warmer than in a brine-rich case, or undergo complete freezing over time. The location of clathrate-rich layers is difficult to assess given the wide range of possible densities for these compounds and for the liquid. Overall, $\mathrm{CH}_{4}$-rich clathrates would be buoyant compared to most liquid solutions, whereas $\mathrm{CH}_{4}$-poor clathrates will segregate as a layer at the bottom of the ocean. Thus, floating $\mathrm{CH}_{4}$-rich clathrates may supply methane to the outer ice shell and the surface/atmosphere of icy satellites.

Acknowledgements The authors are grateful to the organizers of the EuroPlanet-ISSI Workshop Exchange Processes on Icy Satellites, held November 2008 in the inspiring environment of the International Space Science Institute, Bern, Switzerland; two anonymous reviewers for their constructive comments; and O. Grasset for the manuscript handling. We would like to thank G. Tobie for providing the clathrate hydrates densities calculations. This research has been supported by the Helmholtz Association through the research alliance 
Planetary Evolution and Life. A portion of this work was supported by the Jet Propulsion Laboratory, California Institute of Technology, under a contract with the National Aeronautics and Space Administration. Doctors Choukroun, Pappalardo and Vance acknowledge support from the NASA Astrobiology Institute's Astrobiology of Icy Worlds program at the Jet Propulsion Laboratory. Doctors Choukroun and Vance acknowledge support from the NASA Postdoctoral Program administered by Oak Ridge Associated Universities. S. Vance acknowledges support from the Caltech Postdoctoral Program. F. Sohl acknowledges discussions with H. Hussmann, V. Stamenković, and F. W. Wagner.

\section{References}

C.M.O.D. Alexander, M. Fogel, H. Yabuta, G.D. Cody, Geochim. Cosmochim. Acta 71, 4380-4403 (2007) J.D. Anderson, G. Schubert, Geophys. Res. Lett. 34, L02202 (2007). doi:10.1029/2006GL028100

R.N. Anderson, M.D. Zoback, S.H. Hickman, R.L. Newmark, J. Geophys. Res. 90(B5), 3659-3669 (1985)

J.D. Anderson, E.L. Lau, W.L. Sjogren, G. Schubert, W.B. Moore, Nature 384, 541-543 (1996)

J.D. Anderson, G. Schubert, R.A. Jacobson, E.L. Lau, W.B. Moore, W.L. Sjogren, Science 281, 2019-2022 (1998)

S. Atreya, T. Donahue, W. Kuhn, Science 201(4356), 611-613 (1978)

K. Becker, Oceanus 42(1), 2-5 (2000)

K. Becker, R.P.V. Herzen, T.J.G. Francis, R.N. Anderson, J. Honnorez, A.C. Adamson, J.C. Alt, R. Emmermann, P.D. Kempton, H. Kinoshita, C. Laverne, M.J. Mottl, R.L. Newmark, Nature 300(5893), 594-598 (1982)

S. Billings, S. Kattenhorn, Icarus 177, 397-412 (2005)

D. Bockelée-Morvan, J. Crovisier, M.J. Mumma, H.A. Weaver, in Comets II, ed. by M.C. Festou, H.U. Keller, H.A. Weaver (University of Arizona Press, Tucson, 2004), pp. 391-423

A.J. Brearley, in Meteorites and the Early Solar System II, ed. by D.S. Lauretta, H.Y. McSween (University of Arizona Press, Tucson, 2006), pp. 587-624

P. Bridgman, Proc. Am. Assoc. Sci. 47(13), 441-458 (1912)

P. Bridgman, J. Chem. Phys. 5, 964-966 (1937)

R.M. Canup, W.R. Ward, Astron. J. 124, 3404-3423 (2002)

R.M. Canup, W.R. Ward, in Europa, ed. by R.T. Pappalardo, W.B. McKinnon, K. Khurana (University of Arizona Press in collaboration with Lunar and Planetary Institute, Tucson, 2009), pp. 59-83

R.W. Carlson, R.E. Johnson, M.S. Anderson, Science 286(5437), 97-99 (1999)

R.W. Carlson, W.M. Calvin, J.B. Dalton, G.B. Hansen, R.L. Hudson, R.E. Johnson, T.B. McCord, M.H. Moore, in Europa, ed. by R.T. Pappalardo, W.B. McKinnon, K. Khurana (University of Arizona Press in collaboration with Lunar and Planetary Institute, Tucson, 2009), pp. 283-327

J. Castillo-Rogez, J. Geophys. Res. 111, E11005 (2006). doi:10.1029/2004JE002379

J.C. Castillo-Rogez, D.L. Matson, C. Sotin, T.V. Johnson, J.I. Lunine, P.C. Thomas, Icarus 190, 179-202 (2007)

V. Chizhov, J. Appl. Mech. Tech. Phys. 34, 253-263 (1993). Translated from Russian Prikl. Mekh. i Tekhn. Fiz. 2, 113-123

V. Chizhov, O. Nagornov, J. Appl. Mech. Tech. Phys. 31, 378-385 (1990). Translated from Russian Prikl. Mekh. i Tekhn. Fiz. 3, 41-49

M. Choukroun, O. Grasset, J. Chem. Phys. 127, 124506 (2007)

M. Choukroun, O. Grasset, G. Tobie, C. Sotin, Icarus 205, 581-593 (2010)

G.J. Consolmagno, J.S. Lewis, in Jupiter, ed. by T. Gehrels (University of Arizona Press, Tucson, 1976), pp. 1035-1051

G.J. Consolmagno, J.S. Lewis, in Planetary Satellites, ed. by J.A. Burns (University of Arizona Press, Tucson, 1977), pp. 492-500

G.J. Consolmagno, J.S. Lewis, Icarus 34, 280-293 (1978)

A. Coradini, G. Magni, D. Turrini, Space Sci. Rev. (2010, this issue). doi:10.1007/s11214-009-9611-9

S.K. Croft, J.I. Lunine, J. Kargel, Icarus 73, 279-293 (1988)

Dalton et al., Space Sci. Rev. (2010, this issue)

S.J. Desch, J.C. Cook, T.C. Doggett, S.B. Porter, Icarus 202, 694-714 (2009)

Z. Duan, N. Moller, J.H. Weare, Geochim. Cosmochim. Acta 56(7), 2605-2617 (1992)

Y.A. Dyadin, Y.E. Aladko, E.G. Larionov, Mendeleev Commun. 1, 34-35 (1997a)

Y.A. Dyadin, E. Larionov, D. Mirinski, T. Mikina, L. Starostina, Mendeleev Commun. 1, 32-34 (1997b)

Y.A. Dyadin, E. Larionov, Y. Aladko, A. Manakov, F. Zhurko, T. Mikina, V. Kumarov, E. Grachev, J. Struct. Chem. 40, 790-795 (1997c)

Y.A. Dyadin, E. Larionov, Y. Aladko, F. Zhurko, Dokl. Phys. Chem. 378(4-6), 159-161 (2001) 
R. Feistel, W. Wagner, J. Chem. Ref. Data 35(2), 1021-1047 (2006)

A. Fisher, Rev. Geophys. 36(2), 143-182 (1998)

A.T. Fisher, K. Becker, Nature 403(6765), 71-74 (2000)

A.D. Fortes, M. Choukroun, Space Sci. Rev. (2010, this issue)

A.D. Fortes, P.M. Grindrod, S.K. Trickett, L. Vočadlo, Icarus 188(1), 139-153 (2007)

P.E. Geissler, R. Greenberg, G. Hoppa, P. Helfenstein, A. McEwen, R. Pappalardo, R. Tufts, M. Ockert-Bell, R. Sullivan, R. Greeley, M.J.S. Belton, T. Denk, B. Clark, J. Burns, J. Veverka, the Galileo Imaging Team, Nature 391, 368-370 (1998)

C.R. Glein, M.Y. Zolotov, E.L. Shock, Icarus 197, 157-163 (2008)

O. Grasset, High Press. Res. 21, 139-157 (2001)

O. Grasset, J. Pargamin, Planet. Space Sci. 53, 371-384 (2005)

O. Grasset, C. Sotin, F. Deschamps, Planet. Space Sci. 48, 617-636 (2000)

O. Grasset, E. Amiguet, M. Choukroun, High Press. Res. 25(4), 255-265 (2005)

R. Greeley, C.F. Chyba, J.W. Head III, T.B. McCord, W.B. McKinnon, R.T. Pappalardo, P.H. Figueredo, in Jupiter: The Planet, Satellites and Magnetosphere, ed. by F. Bagenal, T.E. Dowling, W.B. McKinnon (Cambridge University Press, Cambridge, 2004), pp. 329-362

R. Greenberg, P. Geissler, G. Hoppa, B.R. Tufts, D.D. Durda, R. Pappalardo, J.W. Head, R. Greeley, R. Sullivan, M.H. Carr, Icarus 135, 64-78 (1998)

R. Greenberg, P. Geissler, G. Hoppa, B.R. Tufts, Rev. Geophys. 40(2), 1004 (2002). doi:10.1029/ 2000RG000096

T. Grindley, J. Lind, J. Chem. Phys. 54(9), 3983-3989 (1971)

P.M. Grindrod, A.D. Fortes, F. Nimmo, D.L. Feltham, J.P. Brodholt, L. Vočadlo, Icarus 197, 137-151 (2008)

S. Henderson, R. Speedy, J. Chem. Phys. 91, 3069-3072 (1987)

H. Hussmann, T. Spohn, Icarus 171, 391-410 (2004)

H. Hussmann, F. Sohl, T. Spohn, Icarus 185, 258-273 (2006)

H. Hussmann, G. Choblet, D.L. Matson, C. Sotin, G. Tobie, T. Van Hoolst, Space Sci. Rev. (2010, this issue)

L. Iess, N.J. Rappaport, P. Tortora, J. Lunine, J.W. Armstrong, S.W. Asmar, L. Somenzi, F. Zingoni, Icarus 190, 585-593 (2007)

L. Iess, N.J. Rappaport, R.A. Jacobson, P. Racioppa, D.J. Stevenson, P. Tortora, J.W. Armstrong, S.W. Asmar, Science 327, 1367-1369 (2010)

T.V. Johnson, Space Sci. Rev. 116, 401-420 (2005)

J.S. Kargel, Icarus 94, 368-390 (1991)

J.S. Kargel, J.Z. Kaye, J.W. Head, G.M. Marion, R. Sassen, J.K. Crowley, O. Prieto-Ballesteros, S.A. Grant, D.L. Hogenboom, Icarus 148, 226-265 (2000)

S.A. Kattenhorn, Icarus 157, 490-506 (2002)

D.S. Kelley, J.A. Karson, G.L. Fruh-Green, D.R. Yoerger, T.M. Shank, D.A. Butterfield, J.M. Hayes, M.O. Schrenk, E.J. Olson, G. Proskurowski, M. Jakuba, A. Bradley, B. Larson, K. Ludwig, D. Glickson, K. Buckman, A.S. Bradley, W.J. Brazelton, K. Roe, M.J. Elend, A. Delacour, S.M. Bernasconi, M.D. Lilley, J.A. Baross, R.T. Summons, S.P. Sylva, Science 307(5714), 1428-1434 (2005)

J.F. Kerridge, M.S. Matthews, Meteorites and the Early Solar System (University of Arizona Press, Tucson, 1988)

K.K. Khurana, M.G. Kivelson, D.J. Stevenson, G. Schubert, C.T. Russell, R.J. Walker, C. Polanskey, Nature 395, 777-780 (1998)

M.G. Kivelson, K.K. Khurana, D.J. Stevenson, L. Bennett, S. Joy, C.T. Russell, R.J. Walker, C. Zimmer, C. Polanskey, J. Geophys. Res. 104(A3), 4609-4626 (1999)

M.G. Kivelson, K.K. Khurana, C.T. Russell, M. Volwerk, R.J. Walker, C. Zimmer, Science 289, 1340-1343 (2000)

M.G. Kivelson, F. Bagenal, W.S. Kurth, F.M. Neubauer, C. Paranicas, J. Saur, in Jupiter, The Planet, Satellites, and Magnetosphere, ed. by F. Bagenal, T. Dowling, W. McKinnon (Cambridge Univ. Press, Cambridge, 2004), pp. 513-536

O.L. Kuskov, V.A. Kronrod, Icarus 151, 204-227 (2001)

O.L. Kuskov, V.A. Kronrod, Icarus 177, 550-569 (2005)

J.S. Lewis, Icarus 15, 174-185 (1971)

J.S. Lewis, Icarus 16, 241-252 (1972)

J.S. Lewis, Space Sci. Rev. 14, 401-411 (1973)

C.R.B. Lister, Geophys. J. R. Astron. Soc. 39(3), 465-509 (1974)

R.D. Lorenz, B.W. Stiles, R.L. Kirk, M.D. Allison, P.P. del Marmo, L. Iess, J.I. Lunine, S.J. Ostro, S. Hensley, Science 319, 1649-1651 (2008)

J.I. Lunine, M. Choukroun, D.J. Stevenson, G. Tobie, in Titan from Cassini-Huygens, ed. by R.H. Brown, J.P. Lebreton, H. Waite (Springer, New York, 2009), pp. 35-59

M.J. Lupo, J.S. Lewis, Icarus 40, 157-170 (1979) 
A. Manakov, V. Voronin, A. Kurnosov, A. Teplykh, E. Larionov, Y. Dyadin, Dokl. Phys. Chem. 378, 148-151 (2001)

A. Manakov, V. Voronin, A. Kurnosov, A. Teplykh, V. Kumarov, Y. Dyadin, J. Inclus. Phenom. Macro. Chem. 48, 11-18 (2004)

G. Marion, R. Farren, A. Komrowski, Cold Regions Sci. Technol. 29, 259-266 (1999)

G.M. Marion, M.V. Mironenko, M.W. Roberts, Comput. Geosci. 36, 10-15 (2010)

B. Martin, W.S. Fyfe, Chem. Geol. 6(3), 185 (1970)

J. Martin, R. Lowell, J. Geophys. Res. 105(B1), 869-882 (2000)

D.L. Matson, J.C. Castillo, J. Lunine, T.V. Johnson, Icarus 187, 569-573 (2007)

T. McCord, G. Hansen, D. Matson, T. Johnson, J. Crowley, F. Fanale, R. Carlson, W. Smythe, P. Martin, C. Hibbitts, J. Granahan, A. Ocampo, J. Geophys. Res. 104, 11827-11852 (1999)

T.B. McCord, G.B. Hansen, C.A. Hibbitts, Science 292, 1523-1525 (2001). doi:10.1126/science.1059916

W.B. McKinnon, Lunar Planet. Sci. Conf. 37, 2444 (2006). Lunar and Planetary Institute

W.B. McKinnon, M.E. Zolensky, Astrobiology 3(4), 879-897 (2003)

W.B. McKinnon, D. Prialnik, S.A. Stern, A. Coradini, in Structure and Evolution of Kuiper Belt Objects and Dwarf Planets, ed. by M.A. Barucci, H. Boehnhardt, D.P. Cruikshank, A. Morbidelli (2008), pp. 213241

L. Minassian, P. Pruzan, A. Soulard, J. Chem. Phys. 75(6), 3064-3072 (1981)

I. Mosqueira, P. Estrada, D. Turrini, Space Sci. Rev. (2010, this issue). doi:10.1007/s11214-009-9614-6

H. Niemann, S. Atreya, S. Bauer, G. Carignan, J. Demick, R. Frost, D. Gautier, J. Haberman, D. Harpold, D. Hunten, G. Israel, J. Lunine, W. Kasprzak, T. Owen, M. Paulkovich, F. Raulin, E. Raaen, S. Way, Nature 438, 779-784 (2005)

H. Palme, A. Jones, in Treatise on Geochemistry, vol. 1, ed. by H.D. Holland, K.K. Turekian (Elsevier, Amsterdam, 2003), pp. 41-61

R. Pappalardo, M. Belton, H. Breneman, M. Carr, C. Chapman, G. Collins, T. Denk, S. Fagents, P. Geissler, B. Giese, R. Greeley, R. Greenberg, J. Head, P. Helfenstein, G. Hoppa, S. Kadel, K. Klaasen, J. Klemaszewski, K. Magee, A. McEwen, J. Moore, W. Moore, G. Neukum, C. Phillips, L. Prockter, G. Schubert, D. Senske, R. Sullivan, B. Tufts, E. Turtle, R. Wagner, K. Williams, J. Geophys. Res. 104, 24015-24056 (1999)

F. Postberg, S. Kempf, J. Schmidt, N. Brilliantov, A. Beinsen, B. Abel, U. Buck, R. Srama, Nature 459, 1098-1101 (2009)

O. Prieto-Ballesteros, J.S. Kargel, M. Fernández-Sampedro, F. Selsis, E.S. Martínez, D.L. Hogenboom, Icarus 177, 491-505 (2005)

L. Prockter et al., Space Sci. Rev. (2010, this issue)

P.M. Schenk, W.B. McKinnon, Icarus 79, 75-100 (1989)

P. Schenk, I. Matsuyama, F. Nimmo, Nature 453, 368-371 (2008)

J. Schmidt, N. Brilliantov, F. Spahn, S. Kempf, Nature 451, 685-688 (2008)

G. Schubert, D.J. Stevenson, K. Ellsworth, Icarus 47, 46-59 (1981)

G. Schubert, T. Spohn, R.T. Reynolds, in Satellites, ed. by J.A. Burns, M.S. Matthews (University of Arizona Press, Tucson, 1986), pp. 224-292

G. Schubert, J.D. Anderson, T. Spohn, W.B. McKinnon, in Jupiter: The Planet, Satellites and Magnetosphere, ed. by F. Bagenal, T.E. Dowling, W.B. McKinnon (Cambridge University Press, Cambridge, 2004), pp. 281-306

G. Schubert, J.D. Anderson, B.J. Travis, J. Palguta, Icarus 188, 345-355 (2007)

G. Schubert, F. Sohl, H. Hussmann, in Europa, ed. by R.T. Pappalardo, W.B. McKinnon, K. Khurana (University of Arizona Press in collaboration with Lunar and Planetary Institute, Tucson, 2009), pp. 353-367

G. Schubert, H. Hussmann, V. Lainey, D.L. Matson, W.B. McKinnon, F. Sohl, C. Sotin, G. Tobie, D. Turrini, T. Van Hoolst, Space Sci. Rev. (2010, this issue)

J. Sclater, C. Jaupart, D. Galson, Rev. Geophys. Space Phys. 18, 269-311 (1980)

E.R.D. Scott, Annu. Rev. Earth Planet. Sci. 35, 577-620 (2007)

J. Seewald, M.Y. Zolotov, T. McCollom, Geochim. Cosmochim. Acta 70, 446-460 (2006)

M.A. Sephton, Nat. Prod. Rep. 19, 292-311 (2002)

F. Simon, G. Glatzel, Z. Anorg. Allg. Chem. 178, 309-316 (1929)

M. Sinha, R. Evans, Mid-Ocean Ridges: Hydrothermal Interactions Between the Lithosphere and Oceans (AGU Press, Washington, 2004)

E.D. Sloan, Clathrate Hydrates of Natural Gases (Marcel Dekker, New York, 1998)

F. Sohl, W.D. Sears, R.D. Lorenz, Icarus 115, 278-294 (1995)

F. Sohl, T. Spohn, D. Breuer, K. Nagel, Icarus 157, 104-119 (2002)

F. Sohl, H. Hussmann, B. Schwentker, T. Spohn, R.D. Lorenz, J. Geophys. Res. 108(E12), 5130 (2003). doi:10.1029/2003JE002044

C. Sotin, J.W. Head III, G. Tobie, Geophys. Res. Lett. 29(8) (2002). doi:1029/2001GL013844 
C. Sotin, G. Mitri, N. Rappaport, G. Schubert, D.J. Stevenson, in Titan from Cassini-Huygens, ed. by R.H. Brown, J.P. Lebreton, H.W. Jr. (Springer, New York, 2009), pp. 61-73

N.A. Spaun, J.W. Head, J. Geophys. Res. 106, 7567-7576 (2001)

T. Spohn, G. Schubert, Icarus 161, 456-467 (2003)

C. Stein, S. Stein, A. Pelayo, in Seafloor Hydrothermal Systems. Geophysical Monograph Series, vol. 91 (American Geophysical Union, Washington, 1995), pp. 425-445

D.J. Stevenson, A.W. Harris, J.I. Lunine, in Satellites, ed. by J.A. Burns, M.S. Matthews (University of Arizona Press, Tucson, 1986), pp. 39-88

R. Sullivan, R. Greeley, K. Homan, J. Klemaszewski, M.J.S. Belton, M.H. Carr, C.R. Chapman, R. Tufts, J.W. Head, R.T. Pappalardo, J. Moore, P. Thomas, the Galileo Imaging Team, Nature 391, 371-373 (1998)

V. Tchijov, R. Baltazar Ayala, G. Cruz León, O. Nagorno, J. Phys. Chem. Solid 65(7), 1277-1283 (2004)

G. Tobie, G. Choblet, C. Sotin, J. Geophys. Res. 108(E11), 5124 (2003). doi:10.1029/2003JE002099

G. Tobie, A. Mocquet, C. Sotin, Icarus 177, 534-549 (2005a)

G. Tobie, O. Grasset, J.I. Lunine, A. Mocquet, C. Sotin, Icarus 175, 496-502 (2005b)

G. Tobie, J.I. Lunine, C. Sotin, Nature 440, 61-64 (2006)

S. Vance, J. Harnmeijer, J. Kimura, H. Hussmann, B. DeMartin, J.M. Brown, Astrobiology 7(6), 987-1005 (2007)

W. Wagner, A. Saul, A. Pruß, J. Phys. Chem. Ref. Data 23(3), 515-525 (1994)

J.H. Waite Jr., W.S. Lewis, B.A. Magee, J.I. Lunine, W.B. McKinnon, C.R. Glein, O. Mousis, D.T. Young, T. Brockwell, J. Westlake, M.J. Nguyen, B.D. Teolis, H.B. Niemann, R.L. McNutt Jr., M. Perry, W.H. Ip, Nature 460, 487-490 (2009)

K. Wang, G. van der Kamp, E.E. Davis, Geophys. J. Int. 139, 763-768 (1999)

J.B. Wash, W.E. Brice, J. Geophys. Res. 89, 9425-9432 (1984)

R. Zimmerman, W. Somerton, M. King, J. Geophys. Res. 91, 12765-12777 (1986)

M.Y. Zolotov, Geophys. Res. Lett. 34, L23203 (2007). doi:10.1029/2007GL031234

M.Y. Zolotov, Lunar Planet. Sci. Conf. 39, 2349 (2008). Lunar and Planetary Institute

M.Y. Zolotov, J. Kargel, in Europa, ed. by R.T. Pappalardo, W.B. McKinnon, K. Khurana (University of Arizona Press in collaboration with Lunar and Planetary Institute, Tucson, 2009), pp. 431-457

M.Y. Zolotov, M.V. Mironenko, Lunar Planet. Sci. Conf. 38, 2340 (2007a). Lunar and Planetary Institute

M.Y. Zolotov, M.V. Mironenko, in Workshop on Ices, Oceans, and Fire: Satellites of the Outer Solar System (Lunar and Planetary Institute, Houston, 2007b), pp. 157-158

M.Y. Zolotov, E.L. Shock, J. Geophys. Res. 106, 32815-32827 (2001)

M.Y. Zolotov, E.L. Shock, J. Geophys. Res. 109, E06003 (2004). doi:10.1029/2003JE002194

M.Y. Zolotov, T. Owen, S. Atreya, H. Niemann, E.L. Shock, EOS Trans. AGU 86(52), $43-44$ (2005). American Geophysical Union 